\title{
Calcium Sensitivity of Neurotransmitter Release Differs at Phasic and Tonic Synapses
}

\author{
Andrew G. Millar, ${ }^{1}$ Robert S. Zucker, ${ }^{2}$ Graham C. R. Ellis-Davies, ${ }^{3}$ Milton P. Charlton, ${ }^{1}$ and Harold L. Atwood ${ }^{1}$ \\ ${ }^{1}$ Department of Physiology, Faculty of Medicine, University of Toronto, Toronto, Ontario, Canada M5S 1A8, ${ }^{2}$ Department of Molecular and Cell Biology, \\ University of California, Berkeley, California 94720, and ${ }^{3}$ Department of Pharmacology and Physiology, College of Medicine, Drexel University, \\ Philadelphia, Pennsylvania 19102
}

The efficacy of synaptic transmission varies greatly among synaptic contacts. We have explored the origins of differences between phasic and tonic crustacean neuromuscular junctions. Synaptic boutons of a phasic motor neuron release three orders of magnitude more quanta to a single action potential and show strong depression to a train, whereas tonic synapses are nearly unresponsive to single action potentials and display an immense facilitation. Phasic and tonic synapses display a similar nonlinear dependence on extracellular $\left[\mathrm{Ca}^{2+}\right]$. We imposed similar spatially uniform intracellular $\left[\mathrm{Ca}^{2+}\right]\left(\left[\mathrm{Ca}^{2+}\right]_{\mathrm{i}}\right)$ steps in phasic and tonic synapses by photolysis of presynaptic caged calcium. $\left[\mathrm{Ca}^{2+}\right]_{\mathrm{i}}$ was measured fluorometrically while transmitter release was monitored electrophysiologically from single boutons in which the $\left[\mathrm{Ca}^{2+}\right]_{\mathrm{i}}$ was elevated. Phasic synapses released the readily releasable pool (RRP) of vesicles at a much higher rate and with a shorter delay than did tonic synapses. Comparison of several kinetic models of molecular events showed that a difference in $\mathrm{Ca}^{2+}$-sensitive priming of vesicles in the RRP combined with a revision of the kinetic $\mathrm{Ca}^{2+}$-binding sequence to the secretory trigger produced the best fit to the markedly different responses to $\mathrm{Ca}^{2+}$ steps and action potentials and of the characteristic features of synaptic plasticity in phasic and tonic synapses. The results reveal processes underlying one aspect of synaptic diversity that may also regulate changes in synaptic strength during development and learning and memory formation.

Key words: synapse; synaptic strength; crayfish; neuromuscular junction; $\mathrm{Ca}^{2+}$ sensitivity; priming

\section{Introduction}

Transmitter release evoked by a nerve impulse ("synaptic strength”) differs enormously among synaptic connections (Atwood and Karunanithi, 2002). Likewise, short-term plasticity is very diverse, ranging from severe depression to dramatic facilitation. This diversity is linked to functional requirements of the neural circuits in which the connections occur. Many variables contribute to differences in presynaptic performance: ion channel number, properties, and location; synaptic vesicle availability; properties of presynaptic proteins regulating $\mathrm{Ca}^{2+}$ dynamics and vesicle exocytosis; and synaptic morphology. For any specific connection, all of these factors must be considered in searching for an explanation of release properties.

Crustacean phasic and tonic glutamatergic motor neurons provide one of the best available examples of synaptic specialization (Kennedy and Takeda, 1965a,b). At synapses of the paired phasic and tonic motor neurons of limb muscles, quantal release from a phasic synapse in response to a single action potential is

\footnotetext{
Received Nov. 18, 2004; revised Jan. 27, 2005; accepted Jan. 28, 2005.

This work was supported by grants from the Canadian Institutes of Health Research (CIHR) (H.L.A., M.P.C.), a CIHR graduate scholarship (A.G.M.), grants from the National Institutes of Health (NIH) and National Science Foundation (R.S.Z.), and a grant from the NIH for development of DMNPE-4 (G.C.R.E.-D.). We thank E. Neher for comments on this manuscript and a gift of brilliant sulfaflavine dye, R. Schneggenburger for valuable advice on transmitter release modeling, and M. Hegström-Wojtowizz and R. English for technical assistance.

Correspondence should be addressed to RobertS. Zucker, Department of Molecular and Cell Biology, University of California, Berkeley, CA 94720. E-mail: zucker@berkeley.edu.

D0I:10.1523/JNEUROSCI.4717-04.2005

Copyright $\odot 2005$ Society for Neuroscience $\quad$ 0270-6474/05/253113-13\$15.00/0
}

typically 100 - to 1000 -fold greater than for a tonic synapse sharing the same postsynaptic muscle cell (Msghina et al., 1998). Moreover, phasic synapses depress rapidly to repeated activation, whereas tonic synapses display facilitation as great as $100,000 \%$ to a $100 \mathrm{~Hz}$ train.

Ultrastructural comparisons of individual synaptic boutons revealed that bouton size, synaptic contact area of individual synapses, and number of synapses per bouton are greater for tonic nerve terminals, contrary to the expectation that these features might be positively correlated with initial release probability (King et al., 1996; Msghina et al., 1998). Estimated $\mathrm{Ca}^{2+}$ entry per synapse is similar for both types of nerve terminals, and no other differences were found that could account for a 1000-fold difference in probability of quantal release (Msghina et al., 1999) and dramatically different forms of plasticity.

In mammalian cultured neurons, the initial probability of transmitter release is proportional to the size of the readily releasable pool (RRP) (Dobrunz and Stevens, 1997; Schikorski and Stevens, 1997). At crayfish terminals, however, the size of the RRP for tonic synaptic boutons is larger than at phasic synapses, whereas the fractional release per impulse of the RRP is 1500-fold smaller (Millar et al., 2002). One mechanism that might explain the differences between tonic and phasic synapses is the $\mathrm{Ca}^{2+}$ dependence of the release process. In this study, we compared release rates during changes in presynaptic intracellular $\left[\mathrm{Ca}^{2+}\right]$ $\left(\left[\mathrm{Ca}^{2+}\right]_{\mathrm{i}}\right)$ produced by flash photolysis of caged $\mathrm{Ca}^{2+}$, which elevates $\left[\mathrm{Ca}^{2+}\right]_{\mathrm{i}}$ rapidly and uniformly throughout terminal 
boutons. For a given $\left[\mathrm{Ca}^{2+}\right]_{\mathrm{i}}$, release rates at phasic synapses were at least one order of magnitude higher than for tonic synapses. Among several models explored, one in which the secretory trigger binds three $\mathrm{Ca}^{2+}$ ions at one site and two $\mathrm{Ca}^{2+}$ ions at another site, with explicit priming of vesicles in the RRP, was best able to account for characteristics of responses to $\left[\mathrm{Ca}^{2+}\right]_{\mathrm{i}}$ steps, single action potentials, and a train of spikes. In this model, tonic and phasic synapses have identical $\mathrm{Ca}^{2+}$ sensitivities of the secretory trigger but have very different states of $\mathrm{Ca}^{2+}$-dependent priming.

\section{Materials and Methods}

Animals and preparation. Freshwater crayfish (Procambarus clarkii; $2-5$ $\mathrm{cm}$ body length) were obtained from Atchafalaya Biological Supply (Raceland, LA) and maintained under standard laboratory conditions as outlined by Bradacs et al. (1997). We used the carpopodite extensor muscle preparation, which is innervated by two excitatory motor axons: one tonic and one phasic. This preparation has been described in detail previously (Bradacs et al., 1997; Msghina et al., 1998).

Solutions. The preparation was dissected and bathed in a modified Van Harreveld's crayfish solution containing the following (in mM): 205.3 $\mathrm{NaCl}, 5.3 \mathrm{KCl}, 13.5 \mathrm{CaCl}_{2}, 2.5 \mathrm{MgCl}_{2}$, and 10 HEPES buffer, $\mathrm{pH}$ 7.4. In some experiments, we further modified the crayfish solution to contain differing concentrations of $\mathrm{Ca}^{2+}$. Solutions contained the following (percentage of normal $\mathrm{Ca}^{2+},\left[\mathrm{CaCl}_{2}\right]$, in $\mathrm{mm}$ ): $0 \%, 0 ; 10 \%, 1.35 ; 25 \%$, $3.38 ; 50 \%, 6.75 ; 75 \%, 10.13 ; 100 \%, 13.5 ; 200 \%, 27$; and $800 \%, 108$. Experiments were performed at room temperature $\left(20 \pm 1^{\circ} \mathrm{C}\right)$.

For "caged calcium" experiments, nerve terminal axons were pressure-injected with a solution containing the following (in $\mathrm{mM}$ ): 50 dimethoxynitrophenyl-EGTA-4 (DMNPE-4), $37.5 \mathrm{CaCl}_{2}, 50 \mathrm{~K}-\mathrm{HEPES}$, 13.2 or 6.6 brilliant sulfaflavine (BS), 1.32 or 0.66 Oregon green 488 BAPTA 6F (OG), and $55 \mathrm{KCl}$ (551-567 mOsm).

UV photolysis. $\left[\mathrm{Ca}^{2+}\right]_{\mathrm{i}}$ was controlled using the recently developed caged $\mathrm{Ca}^{2+}$ chelator DMNPE-4 (Ellis-Davies, 2003). Caged $\mathrm{Ca}^{2+}$ was photolyzed with a flash lamp (T.I.L.L. Photonics, Grafelfing, Germany) or a xenon arc lamp (Optikon, Guelph, Ontario, Canada) controlled with a Uniblitz electronic shutter (Vincent Associates, Rochester, NY). Both devices were coupled to an Optiphot 2 upright microscope (Nikon Canada, Mississauga, Ontario, Canada) via a fused silica light guide and a T.I.L.L. Photonics two-port condenser with $400 \mathrm{~nm}$ dichroic and $400 \mathrm{~nm}$ short-pass filters. The light from the condenser was passed through the microscope to a $40 \times$ UV water-dipping objective (Olympus Optical, Tokyo, Japan). This produced a $20 \times 20 \mu \mathrm{m}$ square of light in the focal plane of the objective. The remaining port on the condenser was coupled through another light guide to a T.I.L.L. Photonics Polychrome IV monochrometer.

When using the flash lamp, we controlled the light intensity by changing the insertion depth of the light guide in the lamp housing. This altered the amount of light entering the light guide by moving the aperture out of the focal plane of the light beam. Gradations were marked on the light guide adapter corresponding to the intensity of light at the output of the objective, which was measured using a fast photodiode in the focal plane of the objective. To monitor flash duration and intensity during experiments, we placed a photodiode at a small opening in the two-port condenser; its output was digitized concurrently with imaging and electrophysiological data.

$\left[\mathrm{Ca}^{2+}\right]_{i}$ measurement. We estimated $\left[\mathrm{Ca}^{2+}\right]_{\mathrm{i}}$ in boutons using the two-dye, dual-excitation wavelength technique of Oheim et al. (1998). This technique measures the ratio of the fluorescence of a singlewavelength, $\mathrm{Ca}^{2+}$-sensitive dye to that of a $\mathrm{Ca}^{2+}$-insensitive dye to correct for dye concentrations and path length. We used $\mathrm{OG}$ as the $\mathrm{Ca}^{2+}$ sensitive dye and $\mathrm{BS}$ as the $\mathrm{Ca}^{2+}$-insensitive dye. Both dyes were pressure-injected into presynaptic terminals along with caged $\mathrm{Ca}^{2+}$. Injected materials were allowed to diffuse to terminal boutons for $30 \mathrm{~min}$. Fluorescence was measured by alternately exciting OG and BS at wavelengths of 480 and $420 \mathrm{~nm}$, respectively, using the T.I.L.L. Photonics monochrometer. Fluorescence emission $(535 \pm 20 \mathrm{~nm})$ was measured by the T.I.L.L. Photonics photodiode system, and the output was digitized at
$10 \mathrm{kHz}$ using a PowerLab data acquisition system (AD Instruments, Colorado Springs, CO). Fluorescence intensities were corrected for tissue fluorescence by subtracting backgrounds measured from a muscle region adjacent to the filled nerve.

$\left[\mathrm{Ca}^{2+}\right]_{i}$ calibrations. Fluorescence measurements were converted to $\left[\mathrm{Ca}^{2+}\right]_{\mathrm{i}}$ by standard methods (Grynkiewicz et al., 1985) using the ratio of OG fluorescence intensity to excitation at $480 \mathrm{~nm}$ divided by BS fluorescence intensity to excitation at $420 \mathrm{~nm}$ for three calibration solutions containing no $\mathrm{Ca}^{2+}\left(R_{\min }\right), 5 \mathrm{mM} \mathrm{Ca}^{2+}\left(R_{\max }\right)$, and $4.5 \mu \mathrm{M} \mathrm{Ca}{ }^{2+}\left(R_{\text {mid }}\right)$. Solution fluorescence was measured from a microcuvette chamber $(20$ $\mu \mathrm{m}$ path length; VitroCom, Mountain Lakes, NJ) placed in the focal plane of the microscope objective, with background subtraction of the cuvette fluorescence filled with water.

$R_{\min }$ was measured for a solution containing the following (in $\mathrm{mM}$ ): 10 $\mathrm{K}_{2} \mathrm{H}_{2}$-DMNPE-4, $1.32 \mathrm{BS}, 0.132 \mathrm{OG}, 15 \mathrm{HCl}, 50 \mathrm{~K}$-HEPES, $10 \mathrm{~K}_{2}$-EGTA, and $175 \mathrm{KCl}, \mathrm{pH}$ 7.4. The $\mathrm{HCl}$ was added to neutralize the DMNPE-4, which was provided in highly basic tetrapotassium form; this produced $15 \mathrm{~mm} \mathrm{KCl}$, and the $\mathrm{K}_{4}$-DMNPE-4 stock solution contained another 5 $\mathrm{mm} \mathrm{KCl}$ (calculated from its degree of protonation estimated from the $\mathrm{pH}$ of a diluted solution). $R_{\max }$ was measured in a solution of (in $\mathrm{mM}$ ): 10 $\mathrm{CaK}_{2}$-DMNPE-4, $1.32 \mathrm{BS}, 0.132 \mathrm{OG}, 50 \mathrm{~K}$-HEPES, $5 \mathrm{CaCl}_{2}$, and $185 \mathrm{KCl}$ plus $20 \mathrm{~mm} \mathrm{KCl}$ from the $\mathrm{K}_{4}$-DMNPE-4, $\mathrm{pH}$ 7.4. The ionic strength of these solutions was $280 \mathrm{~mm}$, the same as for crayfish Ringer's solution. $R_{\text {mid }}$ was measured in a solution containing the $\mathrm{Ca}^{2+}$ buffer 1,3diaminopropane-2-ol- $N, N^{\prime}$-tetraacetic acid (DPTA; Sigma, St. Louis, $\mathrm{MO})$ to control the $\left[\mathrm{Ca}^{2+}\right]$ at an intermediate concentration near the $K_{\mathrm{D}}$ of OG. The solution contained the following (in $\mathrm{mM}$ ): $10 \mathrm{CaK}_{2}$ DMNPE-4, 1.32 BS, 0.132 OG, $20 \mathrm{CaK}_{2}$-DPTA, $30 \mathrm{~K}_{3} \mathrm{H}$-DPTA, 50 $\mathrm{K}$-Trizma, $\mathrm{pH} 8.0$, and $20 \mathrm{KCl}$ produced by neutralization, with a slightly hypertonic ionic strength of $316 \mathrm{~mm}$. At this $\mathrm{pH}$ and ionic strength, DPTA has an effective $K_{\mathrm{D}}$ for $\mathrm{Ca}^{2+}$ of $6.9 \mu \mathrm{M}$ (interpolated from Grimes et al., 1963; Neher and Zucker, 1993; Ohnuma et al., 2001), and the free $\left[\mathrm{Ca}^{2+}\right]$ of the solution should be $4.5 \mu \mathrm{M}$ (confirmed by measurement with $\mathrm{Ca}^{2+}$ ion-selective electrodes; Microelectrodes, Londonderry, $\mathrm{NH}$ ). If $\mathrm{CaK}_{2}$-DMNPE-4 is made stoichiometrically, it will affect neither $\mathrm{pH}$ nor the free $\left[\mathrm{Ca}^{2+}\right]$; therefore, it was produced by titrating DMNPE-4 with $\mathrm{Ca}^{2+}$ using $\mathrm{Ca}^{2+}$-sensitive electrodes. The $\mathrm{pCa}$ of a stock solution containing everything except the DMNPE-4 and the dyes was also checked and confirmed with ion-sensitive electrodes.

Averaging several calibrations, $R_{\max } / R_{\min }$ was 5.32 , whereas without DMNPE- $4, R_{\max } / R_{\min }$ was $\sim 10$, so DMNPE- 4 appears to partially quench OG fluorescence, particularly when bound to $\mathrm{Ca}^{2+}$ (cf. Zucker, 1992), and to reduce its sensitivity to $\mathrm{Ca}^{2+}$. Typical parameter values of $R_{\max }, R_{\min }$, and $R_{\text {mid }}$ were $4.84,0.91$, and 2.9, respectively, corresponding to a $K_{\mathrm{D}}$ of $4.4 \mu \mathrm{M}$. This is substantially higher than the nominal OG $K_{\mathrm{D}}$ of $3 \mu \mathrm{M}$. From the effect of ionic strength on similar indicators (cf. Grynkiewicz et al., 1985; Zhong et al., 2001), a $K_{\mathrm{D}}$ of $4.5 \mu \mathrm{M}$ would be expected, and we used this value for converting fluorescence ratios to $\left[\mathrm{Ca}^{2+}\right]$.

The calibration solutions contained DMNPE-4, OG, and BS in the same ratios (but one-tenth of the concentrations) as the solutions in injection pipettes. Two-dye $\left[\mathrm{Ca}^{2+}\right]_{\mathrm{i}}$ measurements require that the concentration ratio of the dyes remain constant and equal to that used for calibrations. However, OG and BS diffuse at different rates (Oheim et al., 1998); therefore, their ratio is likely to be variable in different boutons and at different times and not equal to that of calibration solutions. This problem, along with variations in the light source spectrum, results in different values of $R_{\min }$ in each experiment. However, $R_{\max } / R_{\min }$ is unaffected by the concentration ratio. The free $\left[\mathrm{Ca}^{2+}\right]$ in our injection solution equals the resting $\left[\mathrm{Ca}^{2+}\right]_{\mathrm{i}}$ in axons $(100 \mathrm{nM})$, which is $2 \%$ of the $K_{\mathrm{D}}$ of OG, so the initial fluorescence ratio should be within $2 \%$ of the range from $R_{\min }$ to $R_{\max }$. We thus used the initial resting fluorescence ratio as $R_{\min }$ for converting $R$ to $\left[\mathrm{Ca}^{2+}\right]_{\mathrm{i}}$ in each experiment.

We tested for effects of bleaching by photolysis flashes using the Cafree or Ca-loaded solutions for determining $R_{\min }$ and $R_{\max }$. A fullintensity flash caused a little less than $5 \%$ bleaching, which would not introduce much error into estimates of $\left[\mathrm{Ca}^{2+}\right]_{\mathrm{i}}$, because this flash brought $\left[\mathrm{Ca}^{2+}\right]_{\mathrm{i}}$ into the middle of the Ca sensitivity range of OG in which bleaching effects are least consequential. 
Predicting $\mathrm{Ca}(\mathrm{t})$ during the flash artifact and the effect of our flashes. To analyze how putative reaction schemes for transmitter release would respond to the time course of $\left[\mathrm{Ca}^{2+}\right]_{\mathrm{i}}, \mathrm{Ca}(t)$, we had to replace the artifact in the $\mathrm{Ca}(t)$ recording with an estimated time course of $\mathrm{Ca}(t)$. This was especially important because, for large $\left[\mathrm{Ca}^{2+}\right]_{\mathrm{i}}$ increases, most transmitter release occurred during the first $50 \mathrm{~ms}$ after the flash, when the artifact obscured the $\mathrm{Ca}(t)$ measurement. The $\mathrm{Ca}(t)$ measurement missed the expected "spike" in $\mathrm{Ca}(t)$ that occurs during the flash (Zucker, 1994; Ellis-Davies, 2003) because of saturation of the detector during the flash. The time course of the saturation artifact over the $50 \mathrm{~ms}$ after the beginning of the flash was similar in boutons that contained just the indicators (data not shown) and in boutons that contained indicators and DMNPE-4 except for the elevated baseline after the flash in DMNPE4-containing boutons.

To calculate the temporal profile of $\mathrm{Ca}(t)$ during and immediately after the flash, we used a simplified reaction scheme for DMNPE-4 similar to that outlined by Ellis-Davies et al. (1996). It included a one-step photolysis process and no $\mathrm{Mg}^{2+}$ binding (which is negligible for DMNPE-4) or binding of $\mathrm{Ca}^{2+}$ to photoproducts (which has negligible effects in the presence of endogenous $\mathrm{Ca}^{2+}$ buffers). The evolution of photolysis of DMNPE-4 was estimated by convolution of the measured time course of the photolysis flash (recorded from reflected light with a photodiode) with the photolysis rate of DMNPE-4. The photolysis efficiency of the flash for DM-nitrophen was estimated using small droplets under oil of a mixture of DM-nitrophen and fluo-3, as described by Zucker (1994), and converted to an efficiency for DMNPE-4 by accounting for the relative UV absorbances and quantum efficiencies of the two caging compounds.

This temporal reduction in [DMNPE-4] was used to drive a series of differential equations representing the binding of DMNPE-4 to $\mathrm{Ca}^{2+}$ and an endogenous cytoplasmic $\mathrm{Ca}^{2+}$ buffer and removal of free $\mathrm{Ca}^{2+}$ by a first-order pump. The equations were solved using a BASIC program and first-order Euler methods. The affinity of DMNPE-4 for $\mathrm{Ca}^{2+}$ depends on $\mathrm{pH}$ and ionic strength; we used a value of $48 \mathrm{~nm}$, the affinity at $\mathrm{pH} 7.2$ in mammalian ionic strength and approximately appropriate for the higher ionic strength $(\sim 280 \mathrm{~mm})$ of crayfish cytoplasm, and a $\mathrm{pH}$ of $\sim 7.3$ (Ellis-Davies et al., 1996), which have opposite effects on affinity. We assumed an on rate of $1.7 \times 10^{7} \mathrm{M} / \mathrm{s}$, the value for the chemically similar compound nitrophenyl-EGTA (Ellis-Davies et al., 1996). Measurement of the fluorescence intensity of indicators coinjected with the DMNPE-4 in boutons set the initial unphotolyzed DMNPE- 4 concentration at 2-4 mM. Ca loading of the injection solution was $75 \%$, resulting in a free $\left[\mathrm{Ca}^{2+}\right]$ of $106 \mathrm{~nm}$. This is close to the resting $\left[\mathrm{Ca}^{2+}\right]_{i}$ in motor nerve terminals (Delaney et al., 1991), so it was assumed that pumping did not alter the DMNPE- $4 \mathrm{Ca}^{2+}$ loading before photolysis.

Endogenous $\mathrm{Ca}^{2+}$ buffering has a buffer ratio of 600 in crayfish opener motor neuron terminals (Tank et al., 1995). Because the endogenous buffer is not saturated by several micromolar $\left[\mathrm{Ca}^{2+}\right]_{\mathrm{i}}$, implying a high capacity, we represented it as $10 \mathrm{~mm} \mathrm{Ca}^{2+}$-binding buffer sites with $16 \mu \mathrm{M} \mathrm{Ca}{ }^{2+}$ affinity, although less buffer of higher affinity remains possible. We assumed an on rate of $5 \times 10^{7} \mathrm{M} / \mathrm{s}$, one-half that of the endogenous $\mathrm{Ca}^{2+}$ buffer in mammalian chromaffin cells (Xu et al., 1997), to account for higher crayfish ionic strength. Simulations included the effects of $\mathrm{Ca}^{2+}$ binding to OG, with affinity of $4.5 \mu \mathrm{M}$ and on rate of $1 \times$ $10^{8} \mathrm{M} / \mathrm{s}$ (typical for BAPTA derivatives, but reduced for crayfish) (Kao and Tsien, 1988; Ellis-Davies et al., 1996). Its concentration was set to $2.6 \%$ that of DMNPE-4, as in the injection mixture, or 52-104 $\mu \mathrm{M}$, as determined by the range of fluorescence intensities of filled boutons compared with the fluorescence of a known concentration in microcuvettes containing cytoplasm-like fluid and correcting for the relative thickness of the cuvettes and boutons.

$\mathrm{Ca}^{2+}$ was removed to a steady-state level of $100 \mathrm{~nm}$ by a nonsaturating pump at a rate of $0.12 / \mathrm{ms}$, which pumps $\mathrm{Ca}^{2+}$ off the native buffer with a time constant of $5 \mathrm{~s}$, as observed experimentally (Tank et al., 1995).

Simulations of the effects of a bright flash on $\mathrm{Ca}(t)$ were compared with $\mathrm{Ca}(t)$ measurements to a full flash in a typical experiment (see Fig. $5 A$ ) and found to match closely for an assumed bouton DMNPE-4 concentration of $2.75 \mathrm{~mm}$ and $\mathrm{Ca}$ indicator concentration of $72 \mu \mathrm{M}$, after subsidence of the flash artifact. This is $5 \%$ of the concentration of mate- rial in the injection pipette, which is typical of the level of filling achievable in boutons within a few hundred micrometers of the injection site; moreover, the dye concentration needed for simulations to match measurements is right in the middle of our estimate of dye concentration from fluorescence intensity $(52-104 \mu \mathrm{M})$. The correspondence between simulations and measurements provides an independent check of our calibration of the $\mathrm{Ca}^{2+}$ sensitivity of OG, as well as a check of our estimate of the photolysis efficiency of our flash apparatus. These concentrations of DMNPE-4 and OG were therefore selected for simulations of a series of eight light flashes at between 15 and $100 \%$ of the full intensity flash, which covered the full range of $\mathrm{Ca}(t)$ measurements in our experiments. The $\mathrm{Ca}(t)$ waveforms generated by these simulations (see Fig. $5 A$ ) were used to predict the responses of reaction schemes used to represent various molecular schemes for transmission at phasic and tonic synapses.

The highest $\left[\mathrm{Ca}^{2+}\right]_{\mathrm{i}}$ level achieved by photolysis in our experiments was $\sim 3.2 \mu \mathrm{M}$. This value seems low but actually matches our predictions, as outlined below. A $3 \mathrm{~mm}$ concentration is far less than the levels exceeding $100 \mu \mathrm{M}$ typically achieved in cells perfused with DM-nitrophen. For example, when mammalian cells are perfused with an $\mathrm{Mg}^{2+}$-free solution, the effective $\mathrm{Ca}^{2+}$ affinity for DM-nitrophen remains at $5 \mathrm{nM}$, and the DM-nitrophen can be almost fully loaded with $\mathrm{Ca}^{2+}$ and still leave $\left[\mathrm{Ca}^{2+}\right]_{\mathrm{i}}$ at $100 \mathrm{~nm}$. Then whatever amount of DM-nitrophen is photolyzed (e.g., $80 \%$ of $10 \mathrm{~mm}=8 \mathrm{~mm}$ ), the same amount of free $\left[\mathrm{Ca}^{2+}\right]$ is released onto a native buffer with a typical buffer ratio of 50 (for most cells), resulting in a $\left[\mathrm{Ca}^{2+}\right]_{\mathrm{i}}$ increase to $160 \mu \mathrm{M}$ (Neher and Zucker, 1993). When injecting nerve terminals, the $\mathrm{Mg}^{2+}$ cannot easily be removed from boutons 100-300 nm away, and this $\mathrm{Mg}^{2+}$ would displace $\mathrm{Ca}^{2+}$ from DMnitrophen, leading to a "loading transient" that itself would activate secretion and might exhaust the RRP before flash experiments begin (Neher and Zucker, 1993). Therefore, we used $\mathrm{Mg}^{2+}$-tolerant DMNPE-4, but its affinity for $\mathrm{Ca}^{2+}$ is one-tenth that of DM-nitrophen, and it can only be $75 \%$ loaded with $\mathrm{Ca}^{2+}$; otherwise, resting $\left[\mathrm{Ca}^{2+}\right]_{\mathrm{i}}$ is increased too much. The quantum efficiency and absorbance of DMNPE-4 are similar to those of DMnitrophen, so a flash would photolyze a similar fraction of DMNPE-4 to release approximately three-fourths as much $\mathrm{Ca}^{2+}$. However, we can only fill boutons by injection with one-fourth the chelator concentration often used when perfusing whole cells. Moreover, crayfish cytoplasm has 12 times the buffer capacity of typical mammalian cells. These considerations lead to the expectation that we should be able to elevate $\left[\mathrm{Ca}^{2+}\right]_{\mathrm{i}}$ to $\sim 2.5 \mu \mathrm{M}$.

Predicting $\mathrm{Ca}(\mathrm{t})$ during an action potential. Vesicle release is triggered by the local increase in $\left[\mathrm{Ca}^{2+}\right]_{\mathrm{i}}$ in "microdomains" because of the entry of $\mathrm{Ca}^{2+}$ ions through clusters of $\mathrm{Ca}^{2+}$ channels with individual "nanodomains" that overlap (Zucker et al., 1999; Augustine et al., 2003). In this situation, the local $C a(t)$ will follow closely the time course of the summed $\mathrm{Ca}^{2+}$ fluxes through the individual channels in the cluster, which corresponds to the macroscopic $\mathrm{Ca}^{2+}$ current (Roberts, 1994). Transmitter release at crayfish motor nerve terminals is governed by $\mathrm{Ca}^{2+}$ entry through P-type $\mathrm{Ca}^{2+}$ channels (Araque et al., 1994; Blundon et al., 1995), the kinetics of which closely resemble those that have been studied exhaustively at the squid giant synapses (Wright et al., 1996). We therefore used a kinetic model of the squid presynaptic $\mathrm{Ca}^{2+}$ current (Llinás et al., 1981) as modified by Llinás et al. (1982), with the temperature set to $19^{\circ} \mathrm{C}$, typical of the present experiments. The kinetic equations were driven with an action potential waveform recorded from motor nerve axons at $19^{\circ} \mathrm{C}$. (No difference was observed between phasic and tonic axons.) The resulting $\mathrm{Ca}(t)$ was almost exactly described by a Gaussian curve, so a closely fitting Gaussian curve $(\sigma=250 \mu \mathrm{s})$ was used to represent $\mathrm{Ca}(t)$. The peak $\left[\mathrm{Ca}^{2+}\right]_{\mathrm{i}}$ amplitude reached during an action potential depends critically on the $\mathrm{Ca}^{2+}$ flux per channel, the number of $\mathrm{Ca}^{2+}$ channels opening near a docked vesicle, their exact distances from the secretory trigger, and the binding kinetics and mobilities of endogenous buffers (Tang et al., 2000; Matveev et al., 2002, 2004). Because none of these is known with sufficient precision, the peak $\left[\mathrm{Ca}^{2+}\right]_{\mathrm{i}}$ amplitude produced by an action potential at the secretory trigger remained a free parameter (cf. Bollmann et al., 2000; Schneggenburger and Neher, 2000).

Electrophysiology. Conjointly with measuring $\left[\mathrm{Ca}^{2+}\right]_{\mathrm{i}}$, neurotransmitter release was assayed by focal extracellular recording at visualized phasic and tonic nerve terminal boutons, using procedures described by 


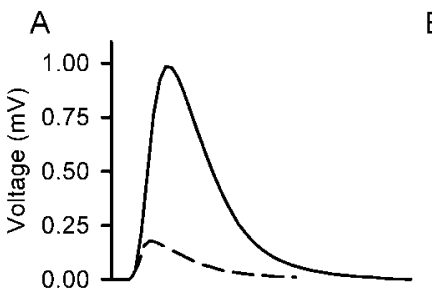

B

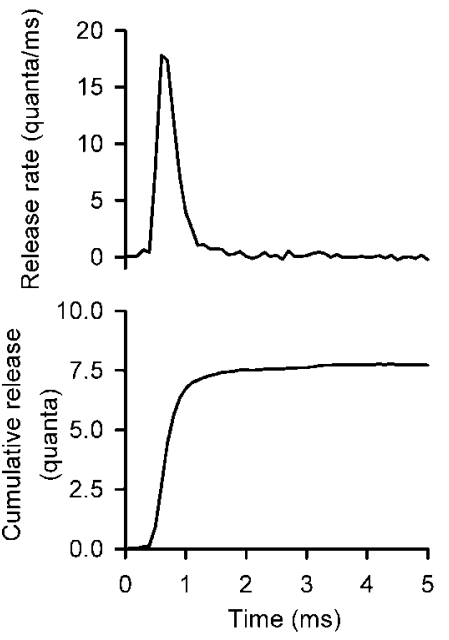

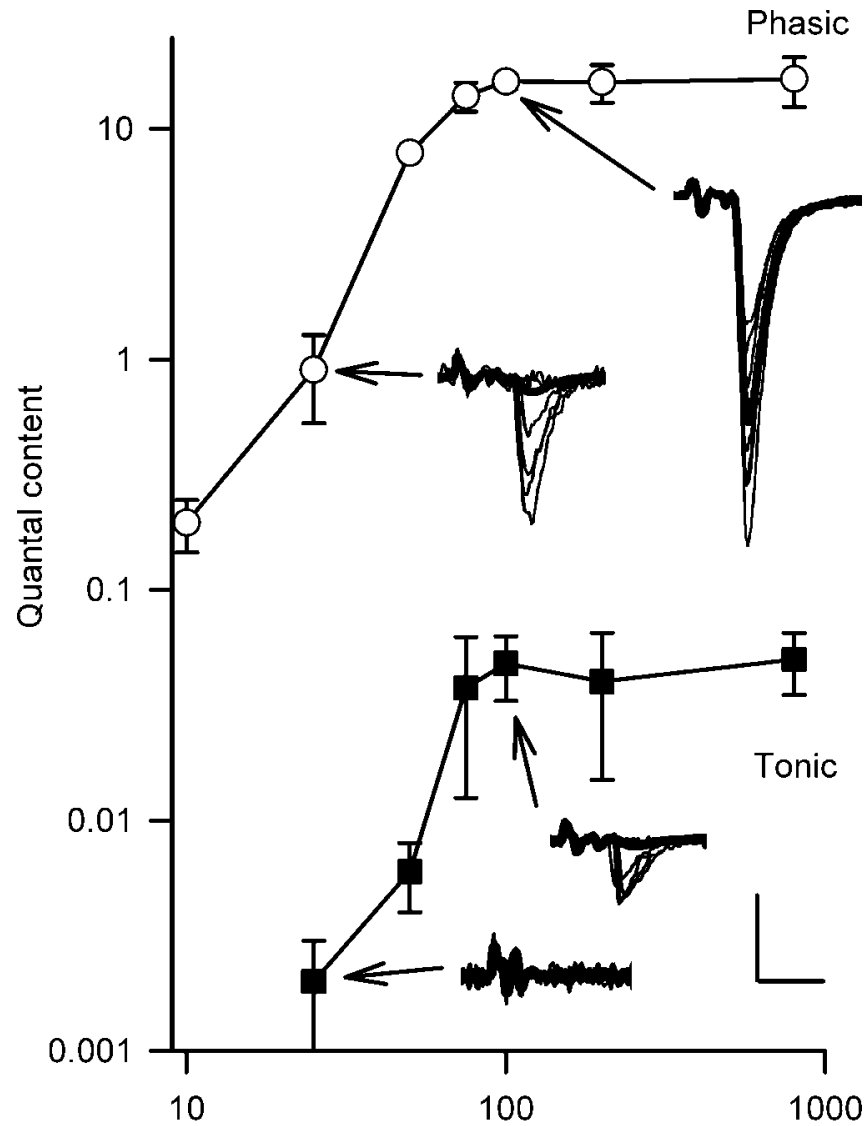

$\left[\mathrm{Ca}^{2+}\right]_{\mathrm{e}}(\%$ of control)

Figure 1. Deconvolution of release rates in a phasic terminal. $A$, An EJC (solid line) evoked by an action potential and an averaged $\mathrm{mEJC}$ (dashed line) are shown in the top trace, followed by the calculated release rate of quantal events in the middle trace and cumulative number of quanta in the bottom trace. $\boldsymbol{B}$, The response to a flash is shown in the top trace, the release rate calculated by deconvolution with $\mathrm{mEJCS}$ is shown in the middle trace, and cumulative release is shown in the bottom trace, to a step $\left[\mathrm{Ca}^{2+}\right]_{\mathrm{i}}$ elevation to $3 \mu \mathrm{m}$.

Msghina et al. (1998). Loose macropatch recordings (Dudel, 1981; Wojtowicz et al., 1994; Cooper et al., 1995) of the presynaptic nerve terminal action potentials and excitatory junction currents (EJCs) were obtained in current-clamp mode from single visualized tonic and phasic terminal boutons. In this mode, the extracellular voltage provides a measure of local postsynaptic current density. As first demonstrated by Ravin et al. (1997), a crayfish bouton can be effectively illuminated and visualized to measure $\left[\mathrm{Ca}^{2+}\right]_{\mathrm{i}}$ while a macro-patch electrode is in place to measure transmitter release from the same bouton.

Release rate determination. To estimate rates of neurotransmitter release in phasic and tonic boutons, we applied a procedure based on Fourier transforms of both EJCs and miniature EJCs (mEJCs) recorded from the same bouton (Van der Kloot, 1988). We used the equation $F[n(t)]=F[\mathrm{EJC}] / F[\mathrm{mEJC}]$, where $F[\mathrm{EJC}]$ is the Fourier transform of an evoked response, $F[\mathrm{mEJC}]$ is the Fourier transform of the averaged quantal events, and $F[n(t)]$ is the Fourier transform of the quantal release rate at time $t$. The inverse Fourier transform of $F[n(t)]$ yields $n(t)$. As shown in Figure $1 A$, deconvolution of an EJC with averaged mEJCs produced a maximum release rate of $17.5 / \mathrm{ms}$, and cumulative release of 7.8 quanta was estimated, which compares well with the quantal content of 7.5 obtained by dividing the EJC area by the mEJC area. Deconvolution of responses to a flash was also used to estimate release rate versus time after the flash; an example is shown in Figure $1 B$.

To evaluate our deconvolution algorithm, we used the procedure proposed by Van der Kloot (1988), in which a predicted evoked response is reconstructed from the calculated release rate and compared with the actual response. We used the equation: $F[$ pred $]=F[\mathrm{mEJC}] \times F[n(t)]$, where $F[$ pred] is the Fourier transform of the predicted evoked event; the inverse Fourier transform of this function did in fact reproduce the actual evoked event. An additional test of the procedure was conducted by constructing an artificial EJP from a series of mEJPs designated as occurring at predetermined times. Deconvolution analysis reproduced the predetermined rate of release and total number of quantal events. Additional tests were conducted on flash-evoked responses in which quanta

Figure 2. Sensitivity of neurotransmitter release to external $\mathrm{Ca}^{2+}$ concentration. Focal recordings of quantal transmitter release were made at individual phasic and tonic boutons with stimulation at $0.2 \mathrm{~Hz}$ as $\left[\mathrm{Ca}^{2+}\right]_{\mathrm{e}}$ was varied from 10 to $800 \%$ of control (13.5 mm). Quantal contents are given for various values of $\left[\mathrm{Ca}^{2+}\right]_{\mathrm{e}}$. Phasic terminals released many more quanta at all values of $\left[\mathrm{Ca}^{2+}\right]_{\mathrm{e}}$. Sample EJC traces are shown for selected data points. Thick traces indicate the average EJC; thin lines are representative EJCs. Calibration: $0.2 \mathrm{mV}, 2 \mathrm{~ms}$. Error bars indicate SEM.

could be detected and counted individually. Our procedure produced release rates and total quantal counts that agreed with estimates derived directly from measuring the time of occurrence of each event. Cumulative quantal contents to an action potential or for a defined period after a flash were estimated by integrating the calculated release rates or by counting quanta in responses where they were individually distinguishable.

Data collection and analysis. Electrophysiological and photometric signals were low-pass-filtered at $5 \mathrm{kHz}$ using a 2004-F Signal Conditioner (Intronix Technologies, Toronto, Ontario, Canada) and subsequently digitized at $10 \mathrm{kHz}$ using a PowerLab/4sp data acquisition system (AD Instruments). Data analysis was performed using Excel (Microsoft, Redmond, WA). Mathematica (Wolfram Research, Champaign, IL) was used for the Fourier analysis.

Modeling molecular reaction schemes. First-order Euler approximations of differential equations were implemented in IgorPro 5.01 (Wavemetrics, Lake Oswego, OR), based on algorithms kindly provided by R. Schneggenburger (Max-Planck Institute for Biophysical Chemistry, Göttingen, Germany). Parameters were varied over a wide range, and we present those giving the best fits of multiple response characteristics to data as determined by eye. Some fits are imperfect; for these, it was found that parameter choices improving fits for one characteristic resulted in worse fits for other characteristics. Thus, an (arbitrary) choice was sometimes made as to which characteristics to fit best. 
A

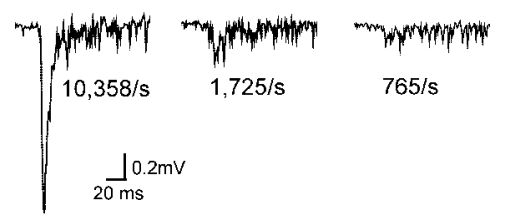

$\mathrm{B}$
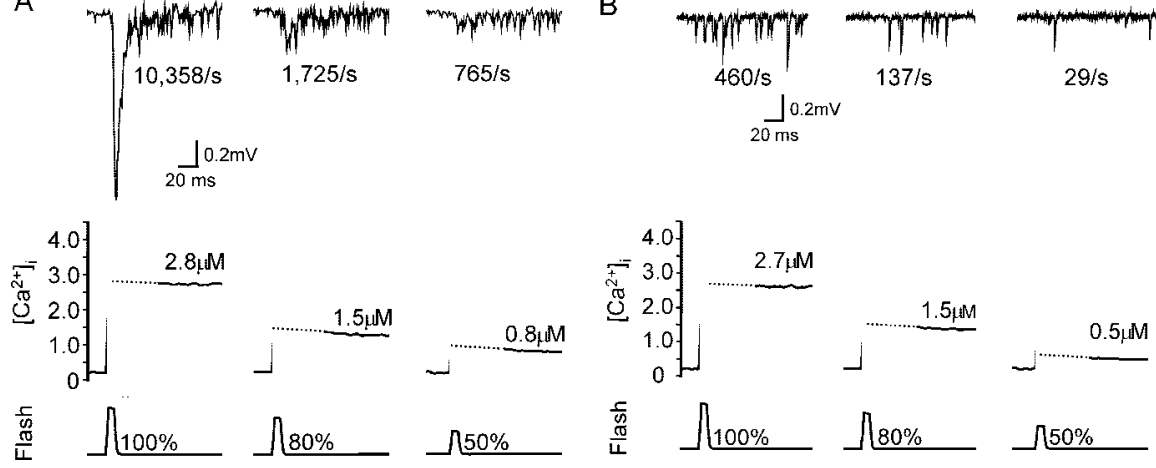

Figure 3. EJCs of phasic and tonic boutons evoked by different $\left[\mathrm{Ca}^{2+}\right]_{i}$ steps. $\boldsymbol{A}$, A phasic bouton loaded with DMNPE-4 was exposed to three UV flashes of varying intensity. Postsynaptic responses to flashes are shown in the top trace, $\left[\mathrm{Ca}^{2+}\right]_{\mathrm{i}}$ responses are shown in the middle trace, and flash intensity is shown in the bottom trace. $\boldsymbol{B}$, Responses to a similar series of flashes in a tonic bouton, showing much less intense release.

\section{Results}

Dependence of transmitter release on extracellular $\left[\mathrm{Ca}^{2+}\right]$

A preliminary experiment compared the dependence of evoked transmitter release on extracellular $\mathrm{Ca}^{2+}$ concentration $\left(\left[\mathrm{Ca}^{2+}\right]_{\mathrm{e}}\right)$. As unbuffered $\left[\mathrm{Ca}^{2+}\right]_{\mathrm{e}}$ was increased from 0 to $800 \%$ of the standard control value $(13.5 \mathrm{~mm})$, quantal content increased from close to zero to a maximum value, which was attained at approximately the standard value of $\left[\mathrm{Ca}^{2+}\right]_{\mathrm{e}}$ (Fig. 2). All recordings contained presynaptic nerve terminal potentials; this indicated that blockage of release was not caused by failure of action potential propagation (Fig. 2, inset). For both phasic and tonic boutons, quantal content (estimated from the ratio of average EJP amplitude to average mEJP amplitude) increased at higher values of $\left[\mathrm{Ca}^{2+}\right]_{\mathrm{e}}$ with a slope of $\sim 3$ in a doublelogarithmic plot (Fig. 2). At $100 \%\left[\mathrm{Ca}^{2+}\right]_{\mathrm{e}}$, phasic nerve terminal boutons produced multiquantal responses with a quantal content of $16.1 \pm 1.2($ mean $\pm \mathrm{SE} ; n=6)$; responses of tonic boutons had a mean quantal content of $0.05 \pm 0.15(n=8)$. Increasing $\left[\mathrm{Ca}^{2+}\right]_{\mathrm{e}}$ beyond $100 \%$ resulted in no further increases in quantal content for phasic or tonic terminal boutons, probably reflecting saturation of $\mathrm{Ca}^{2+}$ influx through $\mathrm{Ca}^{2+}$ channels, a serious limitation of this technique. At lower $\left[\mathrm{Ca}^{2+}\right]_{\mathrm{e}}$, quantal content from phasic terminal boutons was at least two orders of magnitude higher than for tonic boutons. Because the number of phasic or tonic synapses per micrometer of nerve terminal typically differs by less than a factor of 2 (King et al., 1996), macropatch electrodes recorded from similar numbers of active zones of phasic and tonic motor neurons. The large differences in quantal content of phasic and tonic terminals at all concentrations of external $\mathrm{Ca}^{2+}$ may arise from differences in the $\mathrm{Ca}^{2+}$ sensitivity of the transmitter release process.

\section{Dependence of transmitter release on intracellular $\left[\mathrm{Ca}^{2+}\right]$}

As a more direct measure of the $\mathrm{Ca}^{2+}$ sensitivity of the exocytic process, we used photolysis of the caged $\mathrm{Ca}^{2+}$ compound DMNPE-4 to control presynaptic $\left[\mathrm{Ca}^{2+}\right]$. UV flashes of varying intensities produced a range of $\left[\mathrm{Ca}^{2+}\right]_{i}$ elevations, which were estimated by ratiometric fluorimetry using the indicator dyes OG and BS (Oheim et al., 1998) while quantal release rates were recorded. The latter were estimated by deconvolution of the postsynaptic currents with an averaged mEJC recorded from the same bouton. A typical example from a phasic bouton is shown in Figure $3 A$. This bouton was exposed to three flashes (separated in time by $5 \mathrm{~min}$ ) at 100,80 , and $50 \%$ strength; $\left[\mathrm{Ca}^{2+}\right]_{\mathrm{i}}$ was elevated

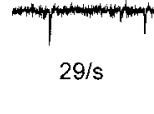

to $2.8,1.5$, and $0.8 \mu \mathrm{M}$, respectively. Before the flashes, the spontaneous transmitter release rate was $\sim 2$ quanta $/ \mathrm{min}$. The elevation to $2.8 \mu \mathrm{M}$ resulted in a rapidly developing exocytic burst with maximum release rate of 12,000 quanta/s, followed by continued release of individual quanta for several hundred milliseconds. The exocytic burst released $\sim 60$ quanta, suggesting that the RRP was secreted within 25 $\mathrm{ms}$. For the first $50 \mathrm{~ms}$ after the burst, release persisted at 280 quanta/s. We interpret this persistent release as reflecting refilling of the RRP from a reserve pool of vesicles, with release of these vesicles soon after their entrance into the RRP. The elevation of $\left[\mathrm{Ca}^{2+}\right]_{\mathrm{i}}$ to $1.5 \mu \mathrm{M}$ resulted in a smaller exocytic burst, with a peak release rate of 1050 quanta/s, followed by continuing release at 250 quanta/s. Elevating $\left[\mathrm{Ca}^{2+}\right]_{\mathrm{i}}$ to $0.8 \mu \mathrm{M}$ evoked a small exocytic burst with peak release rate of 320 quan$\mathrm{ta} / \mathrm{s}$ and continuing release at 200/s after the burst.

Results of comparable UV flashes applied to tonic boutons are illustrated in Figure $3 B$. In this typical tonic bouton, three UV flashes separated by $5 \mathrm{~min}$ were applied at strengths of 100, 80, and $50 \%$, elevating $\left[\mathrm{Ca}^{2+}\right]_{\mathrm{i}}$ to $2.7,1.6$, and $0.5 \mu \mathrm{M}$, respectively. At rest, spontaneous transmitter releases were infrequent, approximately one or two per minute. The $2.7 \mu \mathrm{M}\left[\mathrm{Ca}^{2+}\right]_{\mathrm{i}}$ step resulted in desynchronized release of quanta for $\sim 200 \mathrm{~ms}$, at a maximum rate of 205 quanta/s. The $1.5 \mu \mathrm{M}\left[\mathrm{Ca}^{2+}\right]_{\mathrm{i}}$ elevation elicited a shower of quanta at a lower maximum rate of 137 quan$\mathrm{ta} / \mathrm{s}$ continuing for $\sim 150 \mathrm{~ms}$. The $0.5 \mu \mathrm{M}\left[\mathrm{Ca}^{2+}\right]_{\mathrm{i}}$ step resulted in the release of very few quanta, at a peak rate of 29 quanta/s.

The results of 10 experiments on tonic synapses and 12 on phasic synapses similar to those shown in Figure 3 were compiled to examine the relationship between flash-elevated $\left[\mathrm{Ca}^{2+}\right]_{\mathrm{i}}$ and transmitter release. Figure $4 A$ shows the relationship between release rate for tonic and phasic boutons and $\left[\mathrm{Ca}^{2+}\right]_{i}$ measured immediately after the flash artifact (at $50 \mathrm{~ms}$ ). At $\left[\mathrm{Ca}^{2+}\right]_{\mathrm{i}}$ of $>1.5$ $\mu \mathrm{M}$, phasic release rates (open symbols) reached levels as high as $10,000 /$ s. For values of $\left[\mathrm{Ca}^{2+}\right]_{\mathrm{i}}$ between 0.25 and $1.5 \mu \mathrm{M}$, release rates for phasic boutons were an order of magnitude higher than for tonic boutons for a given $\left[\mathrm{Ca}^{2+}\right]_{\mathrm{i}}$ level. At maximum $\left[\mathrm{Ca}^{2+}\right]_{\mathrm{i}}$ levels reached in this study $(3 \mu \mathrm{M})$, release rates at phasic boutons were nearly 100 times higher than at tonic boutons.

RRP sizes were previously estimated for crayfish tonic and phasic boutons (Millar et al., 2002) as $130 \pm 23$ and $58 \pm 5.6$, respectively. In Figure $4 B$, we divided the total number of quanta released in the first $30 \mathrm{~ms}$ by these mean RRP sizes so that the ordinate represents the percentage of the typical RRP released during this period. At all $\left[\mathrm{Ca}^{2+}\right]_{\mathrm{i}}$ levels of $>2 \mu \mathrm{M}$, phasic boutons released most of the RRP within $30 \mathrm{~ms}$. At $\left[\mathrm{Ca}^{2+}\right]_{\mathrm{i}}$ values between 0 and $1.5 \mu \mathrm{M}$, the percentage of RRP released rose rapidly until reaching its maximum. At tonic synapses, responses to $\left[\mathrm{Ca}^{2+}\right]_{i}$ steps did not display an early clustering of release characteristic of an exocytic burst. Correspondingly, the percentage of RRP released in the first $30 \mathrm{~ms}$ rose gradually with increasing $\left[\mathrm{Ca}^{2+}\right]_{\mathrm{i}}$, reaching only $6-7 \%$ of the mean RRP as $\left[\mathrm{Ca}^{2+}\right]_{i}$ approached 3 $\mu \mathrm{M}$. For a given $\left[\mathrm{Ca}^{2+}\right]_{\mathrm{i}}$ level, the fraction of the RRP released within $30 \mathrm{~ms}$ was $\sim 10$ times higher for phasic than for tonic boutons.

Transmitter release to $\left[\mathrm{Ca}^{2+}\right]_{\mathrm{i}}$ steps was also considerably more sluggish at tonic synapses. Figure $4 C$ plots the time from the 
A

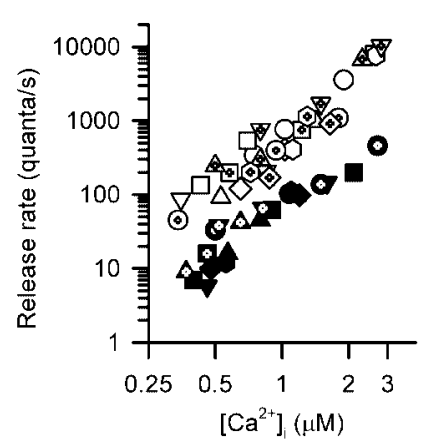

C

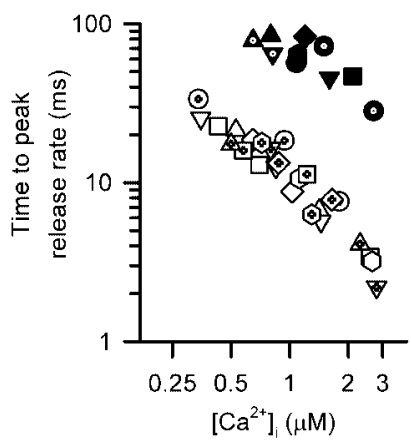

B

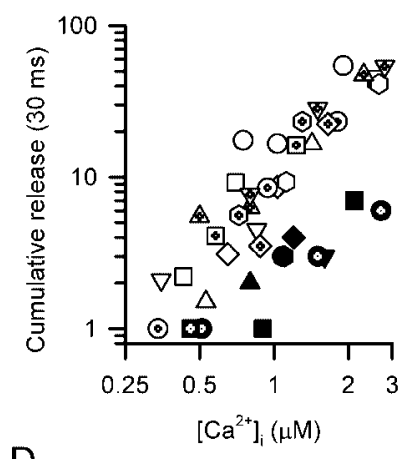

D

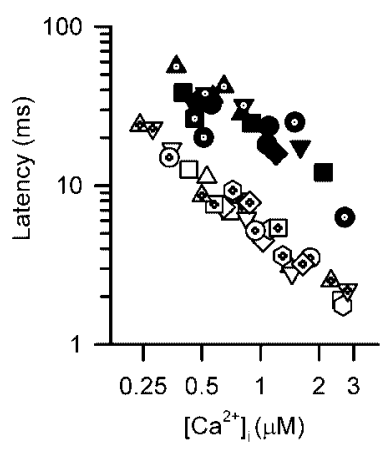

Figure 4. Relationship between $\left[\mathrm{Ca}^{2+}\right]_{\mathrm{i}}$ and transmitter release at phasic and tonic terminals. Trials from phasic experiments are shown with open symbols $(n=12$; each symbol represents data from a different preparation), whereas trials from tonic experiments are shown with filled symbols $(n=10)$. A, Maximum release rate plotted versus $\left[\mathrm{Ca}^{2+}\right]_{\mathrm{i}}$ measured at 50 ms. $\boldsymbol{B}$, Percentage of average RRP released by a flash within $30 \mathrm{~ms}$, plotted against $\left[\mathrm{Ca}^{2+}\right]_{\mathrm{i}} \boldsymbol{C}$, Time to peak rate of release versus amplitude of the $\left[\mathrm{Ca}^{2+}\right]_{i}$ step. $\boldsymbol{D}$, Latency from flash to first quantal release versus amplitude of the $\left[\mathrm{Ca}^{2+}\right]_{i}$ step.

flash to when the release rate reached its maximum. Phasic synapses released their RRP briskly, with peak release rates occurring at $20 \mathrm{~ms}$ for $\left[\mathrm{Ca}^{2+}\right]_{\mathrm{i}}$ steps to $0.5 \mu \mathrm{M}$ to as early as $2 \mathrm{~ms}$ after the flash for $\left[\mathrm{Ca}^{2+}\right]_{\mathrm{i}}$ steps to near $3 \mu \mathrm{M}$. At tonic synapses where few quanta were released, the time to peak frequency could be estimated only approximately: it occurred as late as $80 \mathrm{~ms}$ after a $\left[\mathrm{Ca}^{2+}\right]_{\mathrm{i}}$ step to $0.5 \mu \mathrm{M}$ and at $\sim 30 \mathrm{~ms}$ after a step to near $3 \mu \mathrm{M}$.

Finally, the minimum synaptic delay, or time to the release of the first quantum, was also much shorter at phasic synapses (Fig. 4D). At both types of synapses, release began sooner for larger $\left[\mathrm{Ca}^{2+}\right]_{\mathrm{i}}$ steps. Release at phasic synapses started $7-8 \mathrm{~ms}$ after a $\left[\mathrm{Ca}^{2+}\right]_{\mathrm{i}}$ step to $0.5 \mathrm{~ms}$ or $<2 \mathrm{~ms}$ after a $3 \mu \mathrm{M}$ step. At tonic synapses, release began $30 \mathrm{~ms}$ after a step to $0.5 \mu \mathrm{M}$ and at least $5 \mathrm{~ms}$ after a step to near $3 \mu \mathrm{M}$.

We also performed experiments on three pairs of boutons to estimate the "thresholds" of $\left[\mathrm{Ca}^{2+}\right]_{\mathrm{i}}$ at which quantal release increases above baseline spontaneous levels. Low-intensity pulses of uncaging illumination from a xenon light source were delivered through appropriate neutral density filters and graded to produce several levels of $\left[\mathrm{Ca}^{2+}\right]_{\mathrm{i}}$ in each selected bouton while simultaneously recording quantal events at the same bouton. The threshold value of $\left[\mathrm{Ca}^{2+}\right]_{\mathrm{i}}$ at which an increased rate of quantal events could be detected was $0.4-0.5 \mu \mathrm{M}$ for both synapse types. The threshold value for a given bouton was independent of the rate of rise or final value of $\left[\mathrm{Ca}^{2+}\right]_{\mathrm{i}}$. The threshold values so estimated are considerably lower than the $\left[\mathrm{Ca}^{2+}\right]_{\mathrm{i}}$ values esti-

mated for $\mathrm{Ca}^{2+}$ "nanodomains" or "microdomains" around opened synaptic $\mathrm{Ca}^{2+}$ channels (Neher, 1998). The observation suggests that spontaneous release of vesicles does not increase markedly for values of $\left[\mathrm{Ca}^{2+}\right]_{i}$ near the normal resting level, which is thought to be in the range of 100-200 nM for these neurons (Msghina et al., 1999).

\section{Molecular reaction schemes of the release process}

Phasic synapses are much more sensitive to modest $\left[\mathrm{Ca}^{2+}\right]_{\mathrm{i}}$ elevations than tonic synapses. We wanted to know whether the different responses of phasic and tonic synapses to step rises in $\left[\mathrm{Ca}^{2+}\right]_{\mathrm{i}}$ could quantitatively explain the large differences in quantal content evoked by action potentials. We also wanted to know what type of molecular reaction scheme might underlie the differences in physiology between phasic and tonic synapses.

These questions are linked because relating our findings to spike-evoked release requires application of a kinetic model of the molecular responses to $\left[\mathrm{Ca}^{2+}\right]_{\mathrm{i}}$ steps. The question is whether the likely time course and magnitude of $\left[\mathrm{Ca}^{2+}\right]_{\mathrm{i}}$ changes during an action potential would be expected to evoke quantal contents differing by up to three orders of magnitude when most aspects of the $\left[\mathrm{Ca}^{2+}\right]_{\mathrm{i}}$ step responses differed by only one order of magnitude at phasic and tonic synapses. Our approach to this problem follows that of others (Bollmann et al., 2000; Schneggenburger and Neher, 2000): to build a molecular model of the secretory response to step $\left[\mathrm{Ca}^{2+}\right]_{\mathrm{i}}$ rises and to test whether the model can be driven by a reasonable temporal profile of local $\left[\mathrm{Ca}^{2+}\right]_{\mathrm{i}}$ to release quanta with the time course evoked by an action potential.

Positive cooperativity model, with different secretory triggers We began with the reaction scheme of Heidelberger et al. (1994), devised to account for transmitter release at retinal bipolar synapses, and later extended (Bollmann et al., 2000; Schneggenburger and Neher, 2000) to describe results at the calyx of Held and hair cells (Beutner et al., 2001). The scheme has up to five $\mathrm{Ca}^{2+}$ ions binding sequentially to identical sites on a secretory trigger, with the possibility of positive cooperativity increasing the affinity of successive binding steps, and ending in a $\mathrm{Ca}^{2+}$ independent step representing the kinetics of vesicle fusion:

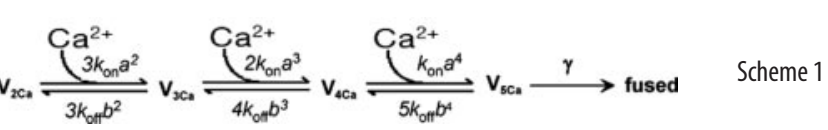

Here, $\mathbf{V}$ refers to vesicles in the RRP, which at rest are unbounded by $\mathrm{Ca}^{2+}$ ions in state $\mathbf{V}$ and are driven by sequentially binding $\mathrm{Ca}^{2+}$ ions until all available sites are occupied, whereupon secretion of the activated vesicle occurs within a time determined by $\gamma$. Positive cooperativity is expressed either by increasing the successive binding rates by factors of $a>1$ or decreasing successive dissociation rates by factors of $b<1$.

The first question was whether Scheme 1 could describe the characteristics of phasic and tonic synapses to step rises in $\left[\mathrm{Ca}^{2+}\right]_{\mathrm{i}}$. We addressed this question by driving the reactions with a time-dependent $\left[\mathrm{Ca}^{2+}\right]_{\mathrm{i}}, \mathrm{Ca}(t)$, calculated for a series of eight flashes that produced $\left[\mathrm{Ca}^{2+}\right]_{\mathrm{i}}$ changes ranging from those obtained with our dimmest flash to our brightest flash. Because of saturation of the photodiode, which distorted the $\mathrm{Ca}(t)$ measurement for up to $50 \mathrm{~ms}$ after the flash, we had to calculate the change in $\left[\mathrm{Ca}^{2+}\right]_{\mathrm{i}}$ for the first $50 \mathrm{~ms}$. Thus, we actually drove the model with a series of $\mathrm{Ca}(t)$ profiles (Fig. $5 \mathrm{~A}$ ) that were fitted to $\mathrm{Ca}(\mathrm{t})$ measurements after subsidence of the flash artifact and 

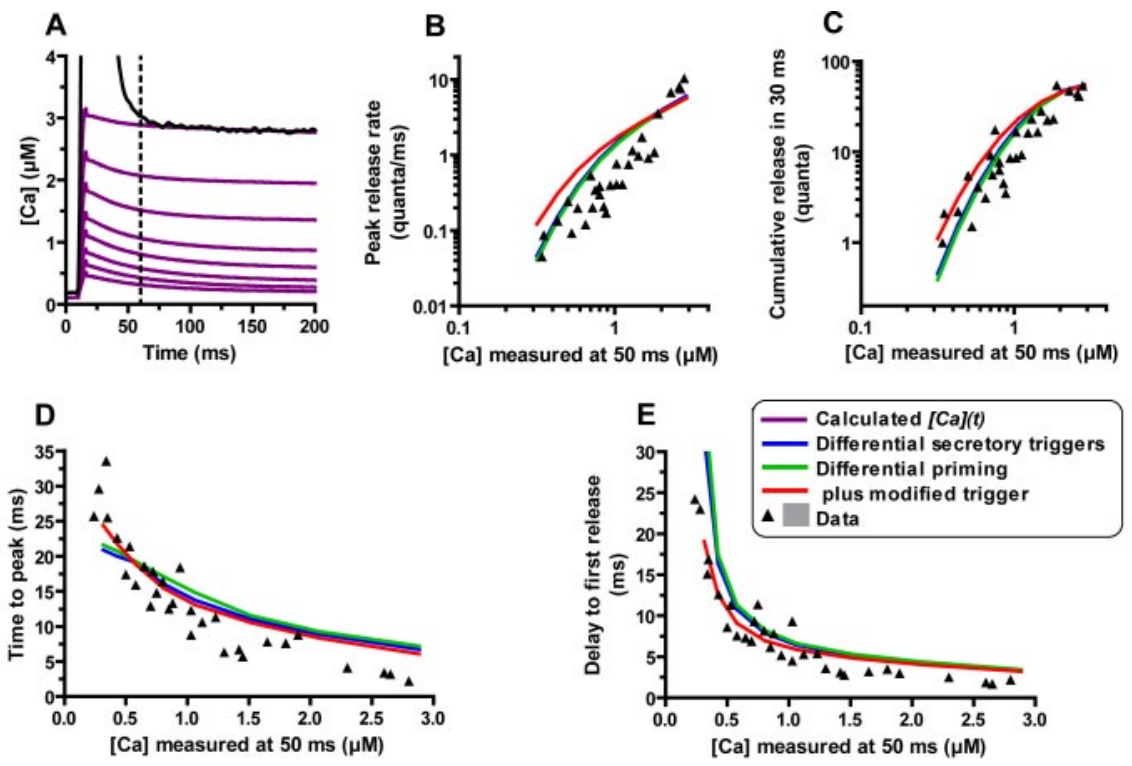

$F$
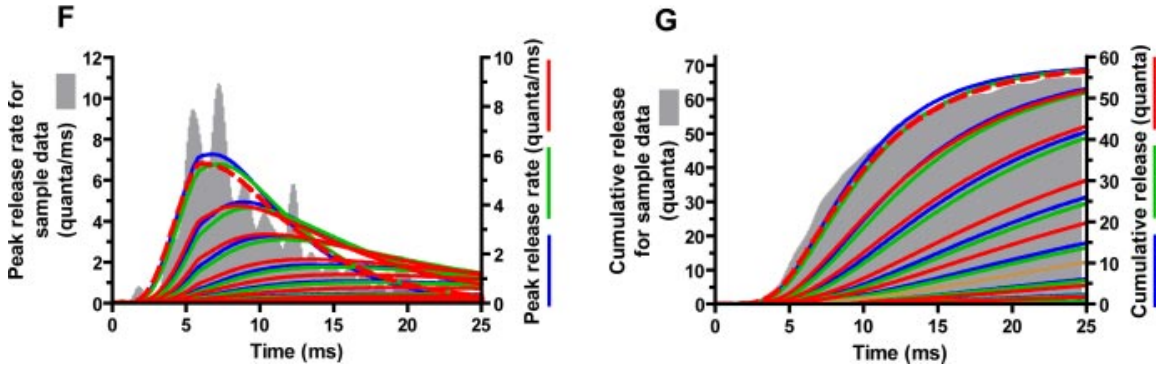

Figure 5. Predicted characteristics of phasic synapse responses to $\mathrm{Ca}^{2+}$ steps of three molecular schemes and comparison with experimental data. $\boldsymbol{A}$, Purple lines represent $\mathrm{C} a(t)$ calculated from simulations of DMNPE-4 photolysis to flashes of varying intensity $(100,80,65,50,40,30,22$, and $15 \%$ of full intensity), reaching levels of $2.9,2.1,1.5,1.1,0.80,0.58,0.43$, and $0.31 \mu \mathrm{M}$, respectively, at $50 \mathrm{~ms}$ after the flash (dotted line). The solid black line is a $\mathrm{Ca}(t)$ measurement to a full-intensity flash from a bouton containing DMNPE-4 and $\mathrm{Ca}^{2+}$ indicator dye. In the remaining curves, simulations for the differential secretory trigger model (Scheme 1; blue lines), differential priming model (Scheme 2; green lines), and differential priming with a modified two-binding site secretory trigger (Scheme 3; red lines) are overlaid on experimental measurements from phasic synapses (filled triangles) of the following characteristics: $\boldsymbol{B}$, maximum release rate; $\boldsymbol{C}$, quantal content accumulated to $30 \mathrm{~ms}$ after the flash; $\boldsymbol{D}$, time to peak release rate $(\boldsymbol{B}) ; \boldsymbol{E}$, delay from flash to first quantal release. $\boldsymbol{F}$, Full predicted time course of the release rate for different $\mathrm{Ca}^{2+}$ steps for all three models overlaid on a histogram of the release rate for a phasic synapse in response to a full flash. $\boldsymbol{G}$, Same as $\boldsymbol{F}$ but for cumulated release. The histograms have been slightly rescaled (left ordinates) to match the predicted amplitudes for the largest responses (dashed lines) to allow for better kinetic comparisons.

included a small " $\mathrm{Ca}^{2+}$ spike" that is a consequence of the finite flash duration, photolysis rate, and $\mathrm{Ca}^{2+}$-binding kinetics of DMNPE-4, as outlined in Materials and Methods.

In Figure $5 B-E$, blue lines plot the characteristics of transmitter release predicted by this scheme to the series of $\left[\mathrm{Ca}^{2+}\right]_{i}$ steps. The $\mathrm{Ca}^{2+}$ dependence of the peak release rate (Fig. $5 B$ ), cumulative quantal release during the first $30 \mathrm{~ms}$ after the flash (Fig. $5 C$ ), the time to the peak release rate after the flash (Fig. 5D), and the delay from the flash to the first quantal release (Fig. $5 E$ ) are plotted along with the experimental measurements for phasic synapses. The $\left[\mathrm{Ca}^{2+}\right]_{\mathrm{i}}$ on the abscissa of each graph corresponds to the $\left[\mathrm{Ca}^{2+}\right]_{\mathrm{i}}$ measured when the flash artifact had dissipated, 50 ms after the flash, and the same time point is used in the simulated $\left[\mathrm{Ca}^{2+}\right]_{\mathrm{i}}$ steps to designate the $\left[\mathrm{Ca}^{2+}\right]_{\mathrm{i}}$ level of the step. Note that this level is less than the highest $\left[\mathrm{Ca}^{2+}\right]_{\mathrm{i}}$ reached at the end of the $7 \mathrm{~ms}$ flash. The peak levels calculated for flashes that produced nominal levels measured at $50 \mathrm{~ms}$ (in parentheses) were (in $\mu \mathrm{M}$ ): 3.21 (2.89), 2.51 (2.07), 2.00 (1.52), 1.53 (1.06), 1.22 (0.805), 0.926 (0.579), $0.700(0.428)$, and $0.513(0.316)$.
For the same range of $\left[\mathrm{Ca}^{2+}\right]_{i}$ steps, we also made more detailed comparisons of the predicted and experimentally determined time courses of release rate (Fig. $5 F$, blue lines) and cumulative release (Fig. $5 G$, blue lines) from a single terminal (gray histograms). The maximum release rate and cumulative release for this particular experiment were somewhat higher than the prediction (Fig. $5 B-E$, rightmost points), so the histograms are rescaled to permit better comparison of predicted and observed time courses. For all simulations, the RRP was fixed at 58 quanta, its average size in phasic synapses (Millar et al., 2002). For the parameters chosen for this simulation $\left(k_{\text {on }}=1.2 \times 10^{8} \mathrm{M} / \mathrm{s} ; k_{\text {off }}=1000 / \mathrm{s}\right.$; cooperativity factors, $a=1$ and $b=0.3$; $\mathrm{Ca}^{2+}$ stoichiometry $\left.=5 ; \gamma=10,000 / \mathrm{s}\right)$, the predictions show reasonable agreement with results. We explored different $\mathrm{Ca}^{2+}$ stoichiometries and the effects of eliminating positive cooperativity $(b=1)$ or introducing it by increasing on rates $(a>1)$ while reducing $k_{\text {on }}$ to keep the on rate of the last step within the physical bounds imposed by $\mathrm{Ca}^{2+}$ dehydration before binding to coordination sites $\left(\sim 10^{9}\right.$ $\mathrm{M} / \mathrm{s}$ ). All of these alternatives produced markedly worse fits to the data.

The same reaction scheme, but with different kinetic parameters, produced a fairly good fit to release from tonic synapses (Fig. 6, blue lines). Figure 6 compares predictions to experimental data just as in Figure 5, except that Figure $6 B$ plots cumulative release in $100 \mathrm{~ms}$ because responses to small $\left[\mathrm{Ca}^{2+}\right]_{\mathrm{i}}$ steps did not even begin until 30-45 ms after the flash (Fig. $6 D)$, and even to the largest $\left[\mathrm{Ca}^{2+}\right]_{\mathrm{i}}$ steps, very little secretion occurred in the first 30 ms (Fig. 6E,F). The fit shown was obtained by reducing $k_{\text {on }}$ to $1.7 \times 10^{7} \mathrm{M} / \mathrm{s}$ and $k_{\text {off }}$ to $140 / s$. The slow kinetics of the responses required slower $\mathrm{Ca}^{2+}$ on and off rates, and this led to a more gradual exhaustion of the RRP (fixed at 130 for tonic synapses) (Millar et al., 2002) with the same basic $\mathrm{Ca}^{2+}$ affinity (8.3 $\mu \mathrm{M})$ as for phasic synapses. For comparison of actual time courses of release rate and cumulative release, the number of quanta released by single flashes was too small to construct a meaningful histogram. Therefore, responses to the three largest $\left[\mathrm{Ca}^{2+}\right]_{\mathrm{i}}$ steps were lumped to form histograms of quantal release rates and cumulative release. These should be compared with a step to the average $\left[\mathrm{Ca}^{2+}\right]_{\mathrm{i}}$ reached in these three flashes, which was $2.2 \mu \mathrm{M}$, corresponding to the second (dashed) blue line from the top in Figure $6, E$ and $F$. The simulated release rates and cumulative release rates for different reaction schemes have been normalized to the peak value for the largest response. The simulations capture the characteristics of the experimental results reasonably well, except that release tapers off more quickly than expected, as seen from the histogram of Figure $6 E$ and the predicted cumulative release within $100 \mathrm{~ms}$ (Fig. 6B). 
Predicting release to action potentials

Our basic hypothesis is that differences in $\mathrm{Ca}^{2+}$ sensitivity to steps leading to exocytosis are responsible for the responses of phasic and tonic synapses to action potentials, whereas the local $\left[\mathrm{Ca}^{2+}\right]_{\mathrm{i}}$-triggering release is similar. Although local $\left[\mathrm{Ca}^{2+}\right]_{\mathrm{i}}$ at the secretory trigger has not been measured, the $\mathrm{Ca}^{2+}$ influx per active zone is similar at phasic and tonic terminals (Msghina et al., 1999). To test this idea, we asked two questions: First, will the expected time course of $\mathrm{Ca}(t)$ at the secretory trigger produce the observed time course of evoked transmitter release if it is used to drive Scheme 1? Second, can the magnitude of release be produced by similar levels of peak $\left[\mathrm{Ca}^{2+}\right]_{\mathrm{i}}$ at phasic and tonic synapses?

To answer these questions, we calculated responses of Scheme 1 to the expected $\mathrm{Ca}(t)$ at secretory triggers near $\mathrm{Ca}^{2+}$ channels during an action potential, derived as explained in Materials and Methods; kinetic parameters were left unchanged from values used to fit phasic and tonic flash responses, respectively. Figure $7 A$ illustrates $C a(t)$ in the top left plot and shows responses in a phasic synapse to an action potential in the bottom left plot. The predicted release time course matched closely the time course of release obtained by deconvolution of EJCs with spontaneous mEJCs at a typical synapse, and the observed quantal content (7.7) equaled that predicted from Scheme 1 using the phasic kinetic parameters, for a local $\left[\mathrm{Ca}^{2+}\right]_{\mathrm{i}}$ reaching $14.7 \mu \mathrm{M}$. Moreover, the same $C a(t)$ reaching a peak $15.4 \mu \mathrm{M}$ drove Scheme 1 with the tonic kinetic parameters to generate a release time course and efficacy matching that measured from a typical tonic terminal (quantal content 0.012 ). The exact magnitude of local $\left[\mathrm{Ca}^{2+}\right]_{\mathrm{i}}$ rise needed to match the quantal content of release to an action potential is sensitive to small changes of release parameters, and the experimental quantal content is also variable from preparation to preparation, especially in tonic synapses. Therefore, the difference between peak $\left[\mathrm{Ca}^{2+}\right]_{i}$ calculated at the secretory trigger during action potentials between tonic and phasic synapses is not significant. Scheme 1, based on different $\mathrm{Ca}^{2+}$ binding rates, can thus account for the differences in natural spike-evoked release, as well as the differences in response to steps of $\left[\mathrm{Ca}^{2+}\right]_{i}$, between phasic and tonic synapses.

Because phasic and tonic synapses respond so differently to a train of action potentials, we decided to test whether Scheme1 can predict the responses to such a stimulus. Figure $7 A$ shows responses of phasic synapses in the bottom right plot to a train of five action potentials at $100 \mathrm{~Hz}$, for which local $\left[\mathrm{Ca}^{2+}\right]_{\mathrm{i}}$ transients at the secretory trigger are shown in the top right plot. After a slight facilitation, depression dominates the responses as the RRP is quickly depleted. The quantal content of the fifth response is reduced to $64 \%$ that of the first action potential. When the same stimulus is used to drive Scheme 1 with the parameters used to fit

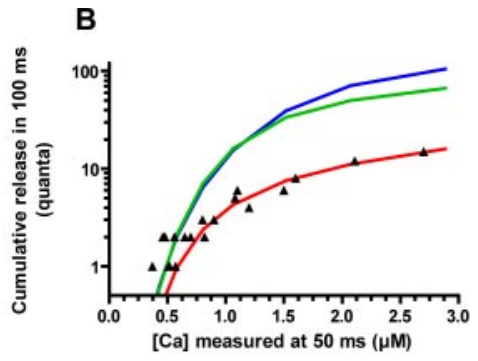

D

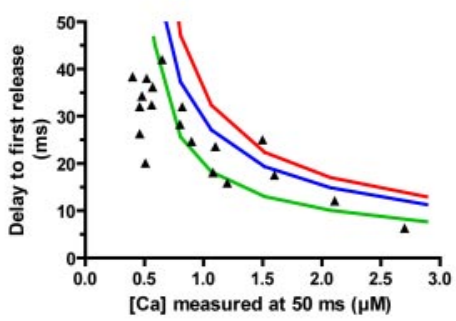

$\mathbf{F}$

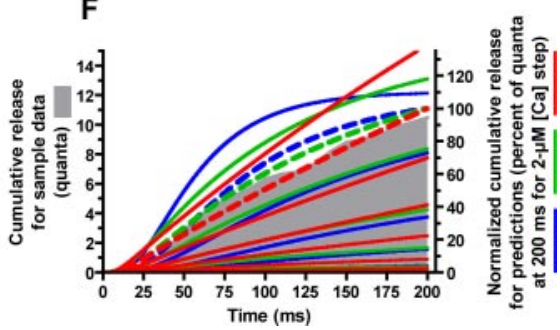

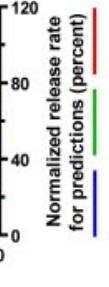

Figure 6. Characteristics of tonic synapse responses. Predictions of the three molecular schemes are compared with experiines (Schemes 1-3), respectively. In $\boldsymbol{F}$, predictions are normalized to the cumulative release at $200 \mathrm{~ms}$ for a $2 \mu \mathrm{m}\left[\mathrm{Ca}^{2+}\right]_{i}$ step, which were 116,89, and 24 quanta for Schemes 1-3, respectively.

tonic synapses, the result is quite different (Fig. $7 B$ ). A dramatic facilitation is produced, with quantal content increasing by the fifth action potential to 120 times $(11,900 \%$ facilitation) that of the first. Although facilitation and depression of tonic and phasic synapses have not been characterized quantitatively, the simulated results resemble qualitatively the reported differences between the two synaptic types in response to $100 \mathrm{~Hz}$ stimulation (Bradacs et al., 1997; Millar et al., 2002).

This suggested that all physiological differences between phasic and tonic synapses might arise from different $\mathrm{Ca}^{2+}$-binding kinetics of the secretory trigger. However, we found a serious problem with Scheme 1 for tonic synapses: the positive cooperativity of binding successive $\mathrm{Ca}^{2+}$ ions and the associated reduction in the off rate slows the dissociation of $\mathrm{Ca}^{2+}$ ions from the secretory trigger when it is almost fully occupied $\left(\mathbf{V}_{4 \mathrm{Ca}}\right)$ to only $3.7 / \mathrm{s}$, generating a huge facilitation. Simulations without positive cooperativity did not fit the data as well and required a slower $k_{\text {off }}$ that again caused facilitation by the slow dissociation of $\mathrm{Ca}^{2+}$ ions after action potentials. Thus, facilitation arises in the simulations from very slow unbinding of $\mathrm{Ca}^{2+}$ ions from the secretory trigger, such that vesicles that were activated but not released by 
the first action potential (i.e., did not quite reach state $\mathbf{V}_{5 \mathrm{Ca}}$ ) do not return to the ground state $\mathbf{V}$ before the next action potential. After successive spikes, more vesicles reside at or close to state $\mathbf{V}_{4 \mathrm{Ca}}$ and are more readily released. Facilitation by this mechanism would be resistant to reduction by injection of exogenous $\mathrm{Ca}^{2+}$ buffers. This contradicts extensive evidence (Delaney et al., 1991; Hochner et al., 1991; Kamiya and Zucker, 1994) that facilitation is linked to the action of residual $\mathrm{Ca}^{2+}$ following action potentials acting on a separate molecular target (Zucker and Regehr, 2002). This target is either a saturable buffer (Rozov et al., 2001; Zucker and Regehr, 2002; Blatow et al., 2003; Felmy et al., 2003; Matveev et al., 2004) or one that directly regulates release (Tang et al., 2000; Matveev et al., 2002). We must therefore reject Scheme 1 because it cannot account for this aspect of the behavior of tonic synapses and seek another mechanism that differentiates tonic from phasic synapses.

\section{Differential priming model}

Much attention has been directed recently to the concept of priming synaptic vesicles for release (Neher, 1998; Martin, 2002; Rettig and Neher, 2002). It is clear that not all vesicles in nerve terminals are perched at the membrane immediately ready for release; at some terminals, only a small fraction of the total supply of vesicles can be released rapidly (to a train of spikes). This RRP may correspond to vesicles in active zones docked at the membrane (Schikorski and Stevens, 1997). Not all of these vesicles are immediately releasable because the maximum number of quanta released by an action potential can be far less than the number of docked vesicles and in some cases may be limited to only one per active zone (Stevens, 2003). The maturation of vesicles into the RRP and then to a state from which they are immediately releasable by the next action potential is often referred to as "priming." The fraction of the RRP released by tetanic stimulation that is fully primed at rest and ready for release by a single action potential might be much higher at phasic synapses. Furthermore, the dramatic facilitation of tonic synapses might correspond to the progressive priming of vesicles during repetitive stimulation. There might be no difference in the properties of the secretory trigger per se between phasic and tonic synapses.

This idea was formulated in Scheme 2, in which a Cadependent priming of vesicles is included explicitly as a process distinct from and anterior to vesicle exocytosis: synapses.

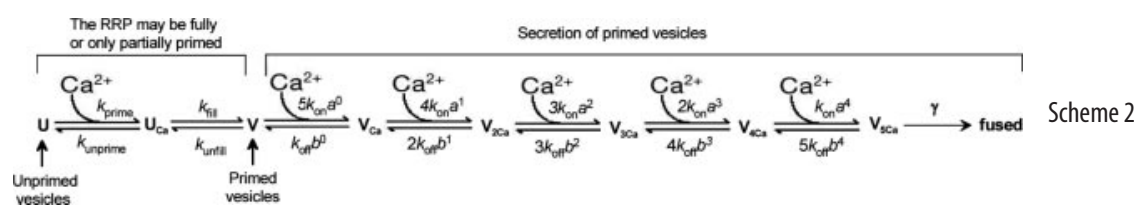

apses as green lines, with $k_{\text {prime }}=4 \times 10^{8} \mathrm{M} / \mathrm{s}, k_{\text {unprime }}=50 / \mathrm{s}$, $k_{\text {fill }}=500 / \mathrm{s}$, and $k_{\text {unfill }}=50 / \mathrm{s}$. At rest $\left(\left[\mathrm{Ca}^{2+}\right]_{\mathrm{i}}=100 \mathrm{nM}\right), 82 \%$ of the RRP is primed, and the simulations are almost indistinguishable from the blue lines of Scheme 1. For tonic synapses, the priming parameters were adjusted so that $k_{\text {prime }}=8 \times 10^{6} \mathrm{M} / \mathrm{s}$, $k_{\text {unprime }}=50 / \mathrm{s}, k_{\text {fill }}=50 / \mathrm{s}$, and $k_{\text {unfill }}=50 / \mathrm{s}$, which leaves only $1.5 \%$ of the RRP primed at rest. The $\mathrm{Ca}^{2+}$ affinity of the priming site was reduced from $125 \mathrm{~nm}$ to $6.25 \mu \mathrm{M}$, and the second step, which might represent the filling of release sites by primed vesicles, was altered to reduce the proportion of vesicles activated by $\mathrm{Ca}^{2+}$ that are fully primed ("efficacy of priming"). The results are shown as green lines in Figure 6. The simulations provide a satisfactory fit to the data, slightly better than Scheme 1 in some respects (e.g., delay to first release) and slightly worse in others (e.g., time to peak), suggesting that a different state of priming might in fact be a major difference between phasic and tonic

Next, we wanted to see whether Scheme 2 could also explain the responses of phasic and tonic synapses to action potentials. To do this, we must consider where in the nerve terminal priming occurs and, in particular, where the $\mathrm{Ca}^{2+}$-sensitive step is located with respect to the $\mathrm{Ca}^{2+}$ channels. It has been pointed out previously (Tang et al., 2000; Matveev et al., 2002) that if a $\mathrm{Ca}^{2+}$ process with high affinity were exposed to the local high $\left[\mathrm{Ca}^{2+}\right]_{\mathrm{i}}$ in the microdomains triggering secretion (Neher, 1998), the site would be saturated after each action potential, and there would be no progressive effect on synaptic transmission. Therefore, we assume that $\mathrm{Ca}^{2+}$ primes vesicles at a site more distant from the nearest $\mathrm{Ca}^{2+}$ channel, perhaps $100-150 \mathrm{~nm}$ away in diffusional distance, which might be physically considerably closer because of restricted diffusion and tortuosity in the crowded space at the base of docked vesicles. We have borrowed the results of previous calculations of $\mathrm{Ca}(t)$ at such a location at crayfish motor nerve terminals during a $100 \mathrm{~Hz}$ train. We used a $\mathrm{Ca}(t)$ profile that is half that shown for $100 \mathrm{~nm}$ from the nearest $\mathrm{Ca}^{2+}$ channel of Matveev et al. (2002), their Figure 1, which is what we might expect for $\left[\mathrm{Ca}^{2+}\right]_{\mathrm{i}} \sim 150 \mathrm{~nm}$ away. This slowly rising and decaying "residual $\mathrm{Ca}^{2+}$," which accumulates during a train, is shown as orange traces in Figure 7, C and D. A similar waveform, arising from channels more distant that those producing the microdomain surrounding docked vesicles, is added to the Gaussian (see Materials and Methods) representing the local microdomain $\mathrm{Ca}^{2+}$ to produce the total $\mathrm{Ca}(t)$ at the secretory trigger.

Considering first a single action potential, we were able to replicate the time course and magnitude of spike-evoked release at both phasic and tonic synapses with this scheme; a peak $\left[\mathrm{Ca}^{2+}\right]_{\mathrm{i}}$ reaching $15.0 \mu \mathrm{M}$ at the secretory trigger released

Here, the RRP has been split into primed (V) and unprimed (U) vesicles, and priming is represented as having $\mathrm{Ca}^{2+}$-dependent and -independent steps, corresponding to Ca-binding and subsequent conformation changes and allowing for independent regulation of kinetics, $\mathrm{Ca}^{2+}$ affinity, and efficacy. The hypothesis we now propose to test is that phasic and tonic synapses differ only in their state of priming, with no difference in the exocytic trigger. We implemented this model by setting the parameters for the secretory trigger to the values used in Scheme 1 for phasic synapses and seeing whether, by altering the parameters regulating priming, we could replicate the behaviors of the two types of synapses.

Figure 5 shows the predictions of this scheme for phasic syn-
7.7 quanta in phasic simulations, matching the quantal content of the phasic terminal recorded in Figure $7 C$. The initial quantal content at a tonic terminal (0.012) and its time course of release were matched by using the parameters derived from fitting Scheme 2 to $\mathrm{Ca}^{2+}$ steps at tonic synapses, but now a peak $\left[\mathrm{Ca}^{2+}\right]_{\mathrm{i}}$ of only $5.5 \mu \mathrm{M}$ was required. Thus, if this scheme is accepted, it might imply that tonic action potentials at tonic synapses generate a smaller peak $\left[\mathrm{Ca}^{2+}\right]_{\mathrm{i}}$ at the secretory trigger than at phasic synapses. The differences in short-term plasticity were also preserved: phasic terminals depressed to one-fifth the initial quantal content by the fifth spike, whereas tonic terminals facilitated 98fold $(9700 \%)$.

The chief difficulty with these simulations lies in the interspike 
intervals. At simulated phasic synapses, transmitter release persists at a rate of $\sim 2-3$ quanta/ms between action potentials; this is much higher than what is observed experimentally (Millar et al., 2002). At tonic synapses, release continues at the same rate or even higher than the evoked release right after the first action potential (at 0.2 quanta/ms) (Fig. $7 D$, bottom right plot). Thus, transmission is not timed to occur mainly right after the action potential, again contradicting experimental observation, and Scheme 2 also suffers from a major flaw.

This behavior is attributable to the positive cooperativity of successive $\mathrm{Ca}^{2+}$ bindings at the secretory trigger. Once the high energy barrier of the first couple of $\mathrm{Ca}^{2+}$ bindings is overcome, the small (micromolar) residual $\mathrm{Ca}^{2+}$ persisting at release sites is sufficient to bind to the remaining high-affinity step(s) and drive to secretion those vesicles that were nearly released by the $\mathrm{Ca}^{2+}$ microdomain of the previous action potential. Moreover, the increasingly slow off rate prevents the $\mathrm{Ca}^{2+}$ ions that have bound from falling off before others from the residual $\mathrm{Ca}^{2+}$ can bind. This problem applies equally to Scheme 1 (data not shown) because it is a characteristic of the secretory trigger with positive cooperativity and multiple sequential $\mathrm{Ca}^{2+}$ binding steps. We conclude that Scheme 2 must also be rejected.

\section{Modification of the secretory trigger}

The problem with Scheme 2 arose from the sequential binding of five $\mathrm{Ca}^{2+}$ ions with positive cooperativity (progressively slowing off rate). However, this does not seem to be a realistic model for $\mathrm{Ca}^{2+}$ binding to synaptotagmin, the putative secretory trigger. Synaptotagmin binds three $\mathrm{Ca}^{2+}$ ions at its $\mathrm{C} 2 \mathrm{~A}$ domain and two at its C2B domain (Bai and Chapman, 2004), and both domains participate in $\mathrm{Ca}^{2+}$-regulated secretion (Stevens and Sullivan, 2003). Although, in principle, $\mathrm{Ca}^{2+}$ ions could bind sequentially to one domain before the other, it is more likely that binding to $\mathrm{C} 2 \mathrm{~A}$ and $\mathrm{C} 2 \mathrm{~B}$ domains proceeds independently, starting with similar affinities at each site. These considerations prompted a modification to the above schemes; we allowed $\mathrm{Ca}^{2+}$ ions to bind simultaneously at the two sites but sequentially at each site with positive cooperativity:

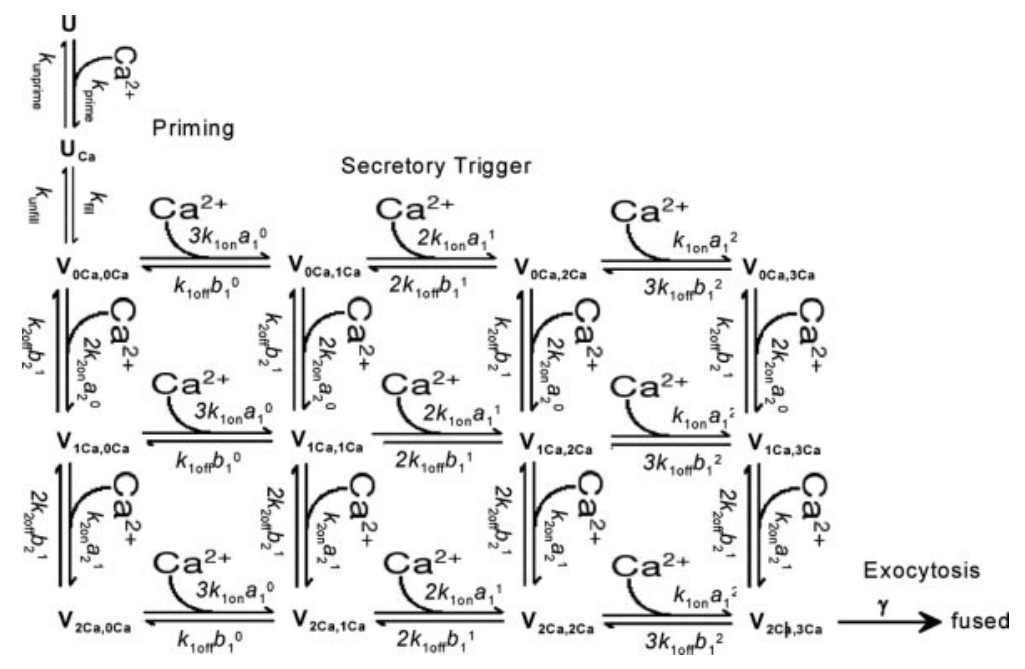

In Scheme 3, there are two classes of $\mathrm{Ca}^{2+}$-binding sites, with separate initial on and off rates $\left(k_{1 \text { on }}\right.$ and $k_{1 \text { off }}, k_{2 \text { on }}$ and $\left.k_{2 \text { off }}\right)$ and forward and backward cooperativity factors $\left(a_{1}\right.$ and $b_{1}, a_{2}$ and $\left.b_{2}\right)$.

We implemented this scheme for phasic synapses by choosing the following parameters: $k_{\text {prime }}=1.0 \times 10^{8} \mathrm{M} / \mathrm{s}, k_{\text {unprime }}=50 / \mathrm{s}$;
Scheme 3

$k_{\text {fill }}=5000 / \mathrm{s}, k_{\text {unfill }}=500 / \mathrm{s}, k_{\text {1on }}=k_{\text {2on }}=1.2 \times 10^{8} \mathrm{M} / \mathrm{s}, k_{1 \text { off }}=$ $k_{\text {2off }}=125 / \mathrm{s}, a_{1}=a_{2}=1, b_{1}=b_{2}=0.5$, and $\gamma=10,000 / \mathrm{s}$. For simplicity, we explored only parameter sets with identical binding constants for the first $\mathrm{Ca}^{2+}$ ion to each of the two classes of binding sites and identical positive cooperativity factors. The results of the simulation are shown as red lines in Figure $5 B-G$. This scheme describes the data as well as the previous two.

For tonic synapses, we obtained a reasonable fit to the data using the identical secretory trigger parameters, but with the following priming site values: $k_{\text {prime }}=6.0 \times 10^{5} \mathrm{M} / \mathrm{s}, k_{\text {unprime }}=$ $40 / \mathrm{s}, k_{\mathrm{fill}}=800 / \mathrm{s}$, and $k_{\mathrm{unfill}}=800 / \mathrm{s}$, producing the red lines in Figure 6. The predicted peak release rates and cumulative releases fit the data better than Schemes 1 and 2, whereas the times to peak and delays to first release are not quite as good. These parameters leave only $0.15 \%$ of the RRP in a fully primed state, compared with $62.5 \%$ for the parameters used for phasic synapses. From Figure 6, E and $F$, the time courses of release and cumulative release are best described by Scheme 3, which is not evident from the fits of individual characteristics of Figure $6 B-E$. The histogram in Figure $6 E$ emphasizes the lack of precision when working with tonic synapses in estimating characteristics such as peak release rate and time to peak used for the plots of Figure 6, $B$ and $D$.

The behavior of Scheme 3 for single action potentials and for five spikes at $100 \mathrm{~Hz}$ is shown in Figure 7, E and F. Initial quantal content and release time course at the phasic synapse were matched with a peak $\left[\mathrm{Ca}^{2+}\right]_{\mathrm{i}}$ of $16.9 \mu \mathrm{M}$ at the secretory trigger; at tonic synapses, a good match was achieved with a peak $\left[\mathrm{Ca}^{2+}\right]_{\mathrm{i}}$ of $10.9 \mu \mathrm{M}$. Simulations of the phasic synapses exhibited a strong depression, to $21 \%$ of the initial quantal content, whereas the tonic synapse simulations facilitated to 28 times the initial release level $(2700 \%$ facilitation). These simulations resemble the depression and facilitation that were observed experimentally (Millar et al., 2002).

In these simulations, facilitation arises from the priming action of residual $\mathrm{Ca}^{2+}$, rather than from a slow kinetic rate constant as in Scheme 1. This may be seen by omitting the priming steps from this scheme, in which case facilitation reached only $268 \%$ (data not shown). Depression arises from depletion of the $R R P$, recovery from which is not included in these simulations. The problem of a large persistent transmitter release in the interspike interval of Scheme 2 as applied to tonic synapses is alleviated. The predicted increase in spontaneous quantal release frequency, to $\sim 1$ quantum per 20 trials in the $10 \mathrm{~ms}$ interval between spikes, resembles what we have observed qualitatively during repetitive stimulation (A. G. Millar, unpublished observations). In conclusion, Scheme 3 provides the best replication yet for the full constellation of differences in release properties of phasic and tonic synapses.

\section{Discussion}

Our key finding is a large difference in the $\mathrm{Ca}^{2+}$ sensitivity and kinetics of the transmitter release machinery between phasic and tonic synapses in response to step rises in $\left[\mathrm{Ca}^{2+}\right]_{\mathrm{i}}$. As pointed out in Introduction, no other property has been found differentiating the two synaptic types that could explain the much stronger efficacy of release from phasic boutons to a single action potential. In the second part of our study, we found that three 
A
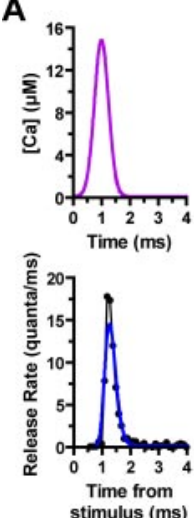

C
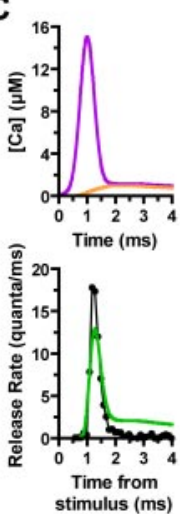

E
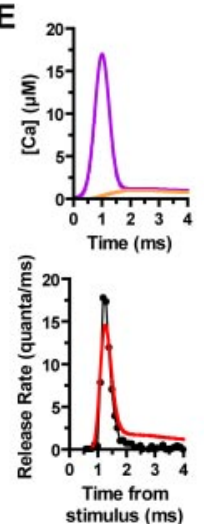
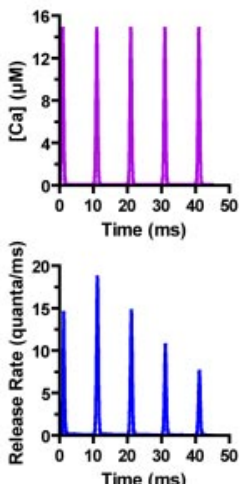

Scheme 1
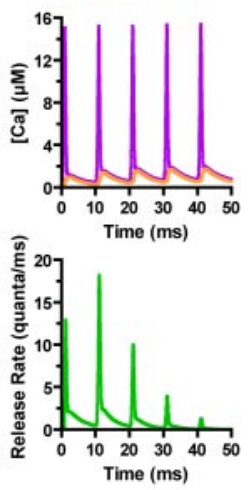

Scheme 2
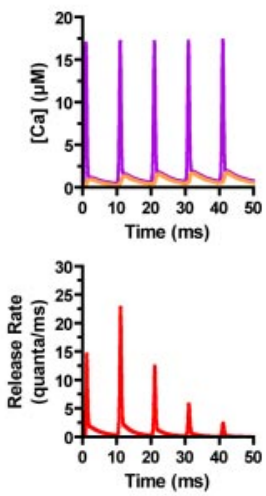

Scheme 3 Differential priming, modified trigger

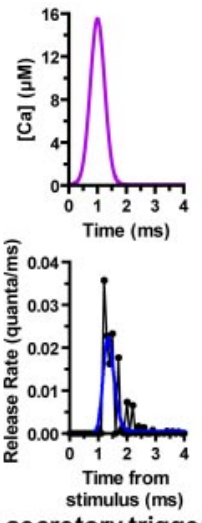

Differential secretory triggers

D

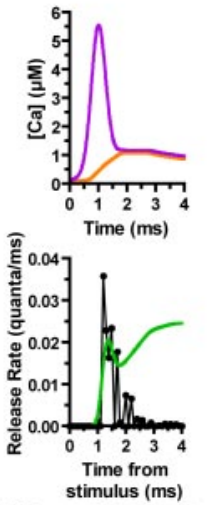

Differential priming

$\mathbf{F}$
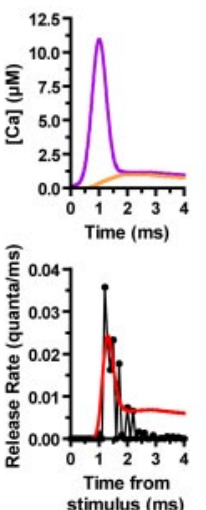

B
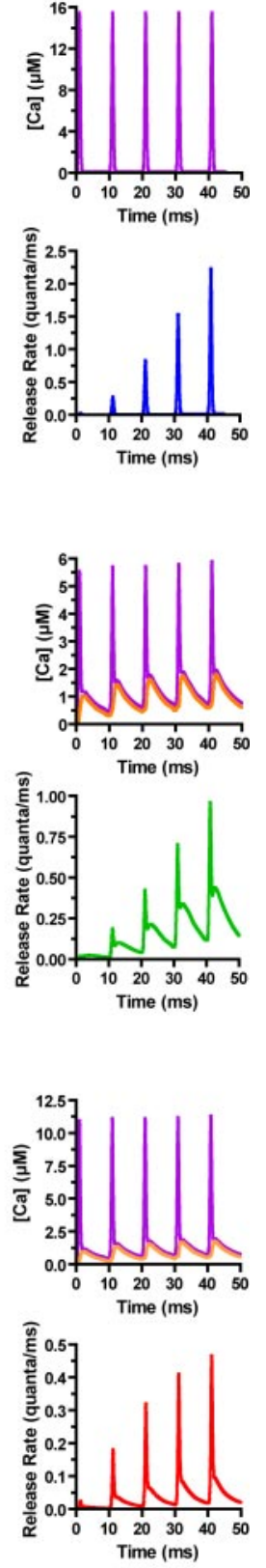

synapses at which depression dominates, and our parameter values are similar to those for this scheme at the calyx of Held (Bollmann et al., 2000; Schneggenburger and Neher, 2000). Applying the first scheme to tonic synapses assumed differences in $\mathrm{Ca}^{2+}$-binding properties of the secretory trigger. Initially, we imagined that tonic synapses bind $\mathrm{Ca}^{2+}$ with lower affinity than phasic synapses, making them less sensitive to $\left[\mathrm{Ca}^{2+}\right]_{\mathrm{i}}$. Such a reduced affinity could arise, for example, from faster $\mathrm{Ca}^{2+}$ dissociation rates from the secretory trigger. In that case, facilitation would not have arisen from Scheme 1, and we would have attributed it to some independent process. However, we were unable to fit the results of our experiments on $\left[\mathrm{Ca}^{2+}\right]_{\mathrm{i}}$ steps by reducing $\mathrm{Ca}^{2+}{ }_{-}$ binding affinity, whether by increasing $\mathrm{Ca}^{2+}$ dissociation rates or increasing $\mathrm{Ca}^{2+}$ association rates; instead, we could only fit the results by reducing both on and off rates for $\mathrm{Ca}^{2+}$ binding, i.e., by slowing the kinetics of $\mathrm{Ca}^{2+}$ binding. Under these conditions, facilitation to a train of action potentials arose from the slow dissociation of $\mathrm{Ca}^{2+}$, contradicting evidence that facilitation is attributable to residual $\mathrm{Ca}^{2+}$.

The second scheme attributed the difference between synapse types to different $\mathrm{Ca}^{2+}$ sensitivities and resting states of priming, with most vesicles in the RRP unprimed at rest in tonic synapses. This scheme could also account for most aspects of responses to steps in $\left[\mathrm{Ca}^{2+}\right]_{\mathrm{i}}$, but it predicted too high an increase in asynchronous release at tonic synapses. In this situation, trigger molecules with three or four $\mathrm{Ca}^{2+}$ ions bound were too sensitive to residual $\mathrm{Ca}^{2+}$ because of the increasing $\mathrm{Ca}^{2+}$ affinities of successive binding steps.

The third scheme was a variant of the priming model in which a modified secretory trigger with $\mathrm{Ca}^{2+}$ binding independently at two binding sites was used, more in keeping with the $\mathrm{Ca}^{2+}$-binding structure of synaptotagmin. This scheme provided the best description of the different responses to $\mathrm{Ca}^{2+}$ steps and action potentials, as well as short-term plasticity and asynchronous release, at phasic and tonic synapses. The $\mathrm{Ca}^{2+}$ association rate derived by fitting this

Figure 7. Simulated responses of three molecular schemes to one spike and to a $100 \mathrm{~Hz}$ train of action potentials and comparison with measured time course of release evoked by one action potential. Phasic synapses are shown on the left $(\boldsymbol{A}, \boldsymbol{C}, \boldsymbol{E})$; toni synapses are shown on the right $(\boldsymbol{B}, \boldsymbol{D}, \boldsymbol{F}) . \boldsymbol{A}, \boldsymbol{B}$, Simulations for Scheme 1 in blue. $\boldsymbol{B}, \boldsymbol{C}$, Simulations for Scheme 2 in green. $\boldsymbol{E}, \boldsymbol{F}$, Simulations for Scheme 3 in red. In each plot, the top row shows the time course of $C a(t)$ at the secretory trigger in purple, to a single action potential at an expanded time scale on the left, and to a train of five spikes at a compressed time scale on the right. Transmitter release to these stimuli is shown directly below them. In simulations that include priming $(\boldsymbol{C}-\boldsymbol{F}), \mathrm{Ca}(t)$ at the putative priming site is also shown in orange, and this residual $\mathrm{Ca}^{2+}$ is included in $\mathrm{Ca}(t)$ at the secretory trigger.

molecular reaction schemes could describe the kinetics and magnitudes of release to a series of $\left[\mathrm{Ca}^{2+}\right]_{i}$ steps and could account for the responses to single spikes and trains of action potentials at phasic and tonic synapses.

We began by with a scheme of the sequential binding of up to five $\mathrm{Ca}^{2+}$ ions to a secretory trigger, followed by a fusion step. This scheme accounted reasonably well for the properties of responses to step rises in $\left[\mathrm{Ca}^{2+}\right]_{\mathrm{i}}$, to the expected time course of local $\left[\mathrm{Ca}^{2+}\right]_{\mathrm{i}}$ during an action potential, and to trains of five action potentials. The phasic synapses resemble many vertebrate scheme to our data $\left(1.2 \times 10^{8} \mathrm{M} / \mathrm{s}\right)$ is similar to estimates from kinetic studies of $\mathrm{Ca}^{2+}$ binding to the C2A domain of synaptotag$\min \left(4 \times 10^{7}-1 \times 10^{8} \mathrm{M} / \mathrm{s}\right)$ (Davis et al., 1999; Millet et al., 2002); moreover, binding of $\mathrm{Ca}^{2+}$ to $\mathrm{C} 2 \mathrm{~A}$ and $\mathrm{C} 2 \mathrm{~B}$ domains appears to be similar, which was a simplifying assumption in our choice of parameters. In this scheme, facilitation arises from the priming of vesicles by $\mathrm{Ca}^{2+}$ (Worden et al., 1997) acting at a site relatively distant from a $\mathrm{Ca}^{2+}$ channel and as such is a variant of the two-site model of facilitation (Tang et al., 2000; Matveev et al., 2002). This new scheme may be closer to what is actually happening at synaptic terminals. 
A finding of general importance is that Scheme 1 also produces too high an asynchronous release rate when the effects of residual $\mathrm{Ca}^{2+}$ are considered. Thus, incorporating residual $\mathrm{Ca}^{2+}$ at the release trigger into simulations of Scheme 1 generates a large interspike release similar to those shown in the bottom left plots of Figure 7, $C$ and $D$ (simulation not shown). This might be a problem for any preparation in which Scheme 1 has been applied (Heidelberger et al., 1994; Bollmann et al., 2000; Schneggenburger and Neher, 2000; Beutner et al., 2001; Felmy et al., 2003) but has not been noted because previous applications of Scheme 1 did not specifically treat the effects of residual $\mathrm{Ca}^{2+}$ on asynchronous release between action potentials. Scheme 3, which attempted to incorporate $\mathrm{Ca}^{2+}$-binding features of synaptotagmin in the way that $\mathrm{Ca}^{2+}$ bound to the secretory trigger, may therefore also be valuable in modeling release at other synapses.

Preliminary experimental results support the concept of $\mathrm{Ca}^{2+}$ dependent priming at tonic synapses. When maximal release rates are imposed by pretreatment with $\mathrm{Cs}^{+}$and high-frequency stimulation (Millar et al., 2002), quantal release always facilitates for a few impulses before attaining a maximal value and then depressing. This effect may be attributable to a priming process initiated early in the train of stimuli. In contrast, phasic synapses do not show an initial priming phase during production of maximal release in $\mathrm{Cs}^{+}$-treated terminals. Steady presynaptic depolarization of tonic nerve endings also potentiates release by action potentials, presumably by increasing steady-state intracellular $\mathrm{Ca}^{2+}$ (Wojtowicz and Atwood, 1983, 1984). When tonic nerve endings are injured by pressure from a macropatch electrode, resting $\left[\mathrm{Ca}^{2+}\right]_{\mathrm{i}}$ rises, and action potentialevoked release increases. These observations, although incomplete, suggest a $\mathrm{Ca}^{2+}$-dependent priming process, which can increase evoked release at tonic synapses, in support of the primingdependent reaction schemes presented here

Alternative formulations of priming to those presented here might also be used to model the data. Phasic synapses were modeled as "preprimed" because of a higher $\mathrm{Ca}^{2+}$-affinity of the priming step; we could equally well have assumed that, at phasic synapses, the priming process is simply absent. Alternatively, we could imagine that only tonic synapses contain a special brake on priming that is relieved by $\mathrm{Ca}^{2+}$. It is also possible that priming acts in parallel or simultaneously with the secretory process (Yamada and Zucker, 1992) rather than anterior to it. Furthermore, our modification of the secretory trigger in Scheme 3 is only the simplest of several we could think of. For example, the two binding sites envisaged in the secretory trigger may have different $\mathrm{Ca}^{2+}$-binding kinetics, multiple synaptotagmins may participate in vesicle release (Hua and Scheller, 2001), and vesicles may be heterogeneous in their release probabilities (Trommershäuser et al., 2003). Thus, the exact details of Scheme 3 remain to be substantiated and may be modified in light of additional data. The major point of the modeling is the demonstration that only a difference in the $\mathrm{Ca}^{2+}$ dependence of priming can explain all the differences between tonic and phasic synapses.

The present results beg the question of the identity of the priming molecule(s). Popular candidates include munc13, rab3interacting molecule, rabphillin, synapsin/Ca-calmodulindependent kinase, SNAP-25 (synaptosome-associated protein of $25 \mathrm{kDa}$ ), and neuronal calcium sensor-1 (Geppert and Südhof, 1998; Hilfiker et al., 1999; Duncan et al., 2000; Lonart, 2002; Martin, 2002; Rettig and Neher, 2002; Zucker, 2003; Heidelberger and Matthews, 2004). Because we are suggesting that the same molecule(s) may be responsible for synaptic facilitation, their identification and characterization become doubly important. A further mystery is how the molecular machinery control- ling the differences between phasic and tonic synapses is regulated. A clue is provided by the discovery that different terminals of a single neuron can display widely different degrees of facilitation and initial release probability that appear to be targetdependent (Atwood, 1967; Bittner, 1968; Atwood and Bittner, 1971; Markram et al., 1998; Reyes et al., 1998), suggesting posttranscriptional and perhaps posttranslational presynaptic modifications under postsynaptic regulation. In the case of crayfish junctions from different motor neurons with very different properties projecting onto the same target, postsynaptic regulation would not seem to be the defining mechanism.

\section{References}

Araque A, Clarac F, Buno W (1994) P-type $\mathrm{Ca}^{2+}$ channels mediate excitatory and inhibitory synaptic transmitter release in crayfish muscle. Proc Natl Acad Sci USA 91:4224-4228.

Atwood HL (1967) Variation in physiological properties of crustacean motor synapses. Nature 215:57-58.

Atwood HL, Bittner GD (1971) Matching of excitatory and inhibitory inputs to crustacean muscle fibers. J Neurophysiol 34:157-170.

Atwood HL, Karunanithi S (2002) Diversification of synaptic strength: presynaptic elements. Nat Rev Neurosci 3:497-516.

Augustine GJ, Santamaria F, Tanaka K (2003) Local calcium signaling in neurons. Neuron 40:331-346.

Bai J, Chapman ER (2004) The C2 domains of synaptotagmin: partners in exocytosis. Trends Biochem Sci 29:143-151.

Beutner D, Voets T, Neher E, Moser T (2001) Calcium dependence of exocytosis and endocytosis at the cochlear inner hair cell afferent synapse. Neuron 29:681-690.

Bittner GD (1968) Differentiation of nerve terminals in the crayfish opener muscle and its functional significance. J Gen Physiol 51:731-758.

Blatow M, Caputi A, Burnashev N, Monyer H, Rozov A (2003) $\mathrm{Ca}^{2+}$ buffer saturation underlies paired pulse facilitation in calbindin-D28kcontaining terminals. Neuron 38:79-88.

Blundon JA, Wright SN, Brodwick MS, Bittner GD (1995) Presynaptic calcium-activated potassium channels and calcium channels at a crayfish neuromuscular junction. J Neurophysiol 73:178-189.

Bollmann JH, Sakmann B, Borst JG (2000) Calcium sensitivity of glutamate release in a calyx-type terminal. Science 289:953-957.

Bradacs H, Cooper RL, Msghina M, Atwood HL (1997) Differential physiology and morphology of phasic and tonic motor axons in a crayfish limb extensor muscle. J Exp Biol 200:677-691.

Cooper RL, Stewart BA, Wojtowicz JM, Wang S, Atwood HL (1995) Quantal measurement and analysis methods compared for crayfish and Drosophila neuromuscular junctions and rat hippocampus. J Neurosci Methods 61:67-78.

Davis AF, Bai J, Fasshauer D, Wolowick MJ, Lewis JL, Chapman ER (1999) Kinetics of synaptotagmin responses to $\mathrm{Ca}^{2+}$ and assembly with the core SNARE complex onto membranes. Neuron 24:363-376.

Delaney K, Tank DW, Zucker RS (1991) Presynaptic calcium and serotonin-mediated enhancement of transmitter release at crayfish neuromuscular junction. J Neurosci 11:2631-2643.

Dobrunz LE, Stevens CF (1997) Heterogeneity of release probability, facilitation, and depletion at central synapses. Neuron 18:995-1008.

Dudel J (1981) The effect of reduced calcium on quantal unit current and release at the crayfish neuromuscular junction. Pflügers Arch 391:35-40.

Duncan RR, Shipston MJ, Chow RH (2000) Double C2 protein: a review. Biochimie 82:421-426.

Ellis-Davies GC (2003) Development and application of caged calcium. Methods Enzymol 360:226-238.

Ellis-Davies GC, Kaplan JH, Barsotti RJ (1996) Laser photolysis of caged calcium: rates of calcium release by nitrophenyl-EGTA and DMnitrophen. Biophys J 70:1006-1016.

Felmy F, Neher E, Schneggenburger R (2003) Probing the intracellular calcium sensitivity of transmitter release during synaptic facilitation. Neuron 37:801-811.

Geppert M, Südhof TC (1998) RAB3 and synaptotagmin: the yin and yang of synaptic membrane fusion. Annu Rev Neurosci 21:75-95.

Grimes JH, Huggard AJ, Wilford SP (1963) The stabilities of the alkaline earth chelate of some polyaminopolycarboxylic acids. J Inororg Nucl Chem 25:1225-1238. 
Grynkiewicz G, Poenie M, Tsien RY (1985) A new generation of $\mathrm{Ca}^{2+}$ indicators with greatly improved fluorescence properties. J Biol Chem 260:3440-3450.

Heidelberger R, Matthews G (2004) Vesicle priming and depriming: a SNAP decision. Neuron 41:311-313.

Heidelberger R, Heinemann C, Neher E, Matthews G (1994) Calcium dependence of the rate of exocytosis in a synaptic terminal. Nature 371:513-515.

Hilfiker S, Pieribone VA, Czernik AJ, Kao HT, Augustine GJ, Greengard P (1999) Synapsins as regulators of neurotransmitter release. Philos Trans R Soc Lond B Biol Sci 354:269-279.

Hochner B, Parnas H, Parnas I (1991) Effects of intra-axonal injection of $\mathrm{Ca}^{2+}$ buffers on evoked release and on facilitation in the crayfish neuromuscular junction. Neurosci Lett 125:215-218.

Hua Y, Scheller RH (2001) Three SNARE complexes cooperate to mediate membrane fusion. Proc Natl Acad Sci USA 98:8065-8070.

Kamiya H, Zucker RS (1994) Residual $\mathrm{Ca}^{2+}$ and short-term synaptic plasticity. Nature 371:603-606.

Kao JP, Tsien RY (1988) $\mathrm{Ca}^{2+}$ binding kinetics of fura- 2 and azo-1 from temperature-jump relaxation measurements. Biophys J 53:635-639.

Kennedy D, Takeda K (1965a) Reflex control of abdominal flexor muscles in the crayfish. I. The twitch system. J Exp Biol 43:211-227.

Kennedy D, Takeda K (1965b) Reflex control of abdominal flexor muscles in the crayfish. II. The tonic system. J Exp Biol 43:229-246.

King MJ, Atwood HL, Govind CK (1996) Structural features of crayfish phasic and tonic neuromuscular terminals. J Comp Neurol 372:618-626.

Llinás R, Steinberg IZ, Walton K (1981) Presynaptic calcium currents in squid giant synapse. Biophys J 33:289-321.

Llinás R, Sugimori M, Simon SM (1982) Transmission by presynaptic spike-like depolarization in the squid giant synapse. Proc Natl Acad Sci USA 79:2415-2419.

Lonart G (2002) RIM1: an edge for presynaptic plasticity. Trends Neurosci 25:329-332.

Markram H, Wang Y, Tsodyks M (1998) Differential signaling via the same axon of neocortical pyramidal neurons. Proc Natl Acad Sci USA 95:5323-5328.

Martin TF (2002) Prime movers of synaptic vesicle exocytosis. Neuron 34:9-12.

Matveev V, Sherman A, Zucker RS (2002) New and corrected simulations of synaptic facilitation. Biophys J 83:1368-1373.

Matveev V, Zucker RS, Sherman A (2004) Facilitation through buffer saturation: constraints on endogenous buffering properties. Biophys J 86:2691-2709.

Millar AG, Bradacs H, Charlton MP, Atwood HL (2002) Inverse relationship between release probability and readily releasable vesicles in depressing and facilitating synapses. J Neurosci 22:9661-9667.

Millet O, Bernadó P, Garcia J, Rizo J, Pons M (2002) NMR measurement of the off rate from the first calcium-binding site of the synaptotagmin $\mathrm{IC}_{2} \mathrm{~A}$ domain. FEBS Lett 516:93-96.

Msghina M, Govind CK, Atwood HL (1998) Synaptic structure and transmitter release in crustacean phasic and tonic motor neurons. J Neurosci 18:1374-1382.

Msghina M, Millar AG, Charlton MP, Govind CK, Atwood HL (1999) Calcium entry related to active zones and differences in transmitter release at phasic and tonic synapses. J Neurosci 19:8419-8434.

Neher E (1998) Vesicle pools and $\mathrm{Ca}^{2+}$ microdomains: new tools for understanding their roles in neurotransmitter release. Neuron 20:389-399.

Neher E, Zucker RS (1993) Multiple calcium-dependent processes related to secretion in bovine chromaffin cells. Neuron 10:21-30.

Oheim M, Naraghi M, Muller TH, Neher E (1998) Two dye two wavelength excitation calcium imaging: results from bovine adrenal chromaffin cells. Cell Calcium 24:71-84.

Ohnuma K, Whim MD, Fetter RD, Kaczmarek LK, Zucker RS (2001) Presynaptic target of $\mathrm{Ca}^{2+}$ action on neuropeptide and acetylcholine release in Aplysia californica. J Physiol (Lond) 535:647-662.

Ravin R, Spira ME, Parnas H, Parnas I (1997) Simultaneous measurement of intracellular $\mathrm{Ca}^{2+}$ and asynchronous transmitter release from the same crayfish bouton. J Physiol (Lond) 501:251-262.
Rettig J, Neher E (2002) Emerging roles of presynaptic proteins in $\mathrm{Ca}^{++}$ triggered exocytosis. Science 298:781-785.

Reyes A, Lujan R, Rozov A, Burnashev N, Somogyi P, Sakmann B (1998) Target-cell-specific facilitation and depression in neocortical circuits. Nat Neurosci 1:279-285.

Roberts WM (1994) Localization of calcium signals by a mobile calcium buffer in frog saccular hair cells. J Neurosci 14:3246-3262.

Rozov A, Burnashev N, Sakmann B, Neher E (2001) Transmitter release modulation by intracellular $\mathrm{Ca}^{2+}$ buffers in facilitating and depressing nerve terminals of pyramidal cells in layer $2 / 3$ of the rat neocortex indicates a target cell-specific difference in presynaptic calcium dynamics. J Physiol (Lond) 531:807-826.

Schikorski T, Stevens CF (1997) Quantitative ultrastructural analysis of hippocampal excitatory synapses. J Neurosci 17:5858-5867.

Schneggenburger R, Neher E (2000) Intracellular calcium dependence of transmitter release rates at a fast central synapse. Nature 406:889-893.

Stevens CF (2003) Neurotransmitter release at central synapses. Neuron 40:381-388.

Stevens CF, Sullivan JM (2003) The synaptotagmin C2A domain is part of the calcium sensor controlling fast synaptic transmission. Neuron 39:299-308.

Tang Y, Schlumpberger T, Kim T, Lueker M, Zucker RS (2000) Effects of mobile buffers on facilitation: experimental and computational studies. Biophys J 78:2735-2751.

Tank DW, Regehr WG, Delaney KR (1995) A quantitative analysis of presynaptic calcium dynamics that contribute to short-term enhancement. J Neurosci 15:7940-7952.

Trommershäuser J, Schneggenburger R, Zippelius A, Neher E (2003) Heterogeneous presynaptic release probabilities: functional relevance for short-term plasticity. Biophys J 84:1563-1579.

Van der Kloot W (1988) Estimating the timing of quantal releases during end-plate currents at the frog neuromuscular junction. J Physiol (Lond) 402:595-603.

Wojtowicz JM, Atwood HL (1983) Maintained depolarization of synaptic terminals facilitates nerve-evoked transmitter release at a crayfish neuromuscular junction. J Neurobiol 14:385-390.

Wojtowicz JM, Atwood HL (1984) Presynaptic membrane potential and transmitter release at the crayfish neuromuscular junction. J Neurophysiol 52:99-113.

Wojtowicz JM, Marin L, Atwood HL (1994) Activity-induced changes in synaptic release sites at the crayfish neuromuscular junction. J Neurosci 14:3688-3703.

Worden MK, Bykhovskaia M, Hackett JT (1997) Facilitation at the lobster neuromuscular junction: a stimulus-dependent mobilization model. J Neurophysiol 78:417-428.

Wright SN, Brodwick MS, Bittner GD (1996) Presynaptic calcium currents at voltage-clamped excitor and inhibitor nerve terminals of crayfish. J Physiol (Lond) 496:347-361.

Xu T, Naraghi M, Kang H, Neher E (1997) Kinetic studies of $\mathrm{Ca}^{2+}$ binding and $\mathrm{Ca}^{2+}$ clearance in the cytosol of adrenal chromaffin cells. Biophys J 73:532-545.

Yamada WM, Zucker RS (1992) Time course of transmitter release calculated from simulations of a calcium diffusion model. Biophys J 61:671-682.

Zhong N, Beaumont V, Zucker RS (2001) Roles for mitochondrial and reverse mode $\mathrm{Na}^{+} / \mathrm{Ca}^{2+}$ exchange and the plasmalemma Ca ${ }^{2+}$ ATPase in post-tetanic potentiation at crayfish neuromuscular junctions. J Neurosci 21:9598-9607.

Zucker R (1994) Photorelease techniques for raising or lowering intracellular $\mathrm{Ca}^{2+}$. Methods Cell Biol 40:31-63.

Zucker RS (1992) Effects of photolabile calcium chelators on fluorescent calcium indicators. Cell Calcium 13:29-40.

Zucker RS (2003) NCS-1 stirs somnolent synapses. Nat Neurosci 6:1006-1008

Zucker RS, Regehr WG (2002) Short-term synaptic plasticity. Annu Rev Physiol 64:355-405.

Zucker RS, Kullmann DM, Bennett M (1999) Release of neurotransmitters. In: Fundamental neuroscience (Zigmond MJ, Bloom FL, Landis SC, Roberts JL, Squire LR, eds), pp 155-192. San Diego: Academic. 